\title{
Natural and induced environment around the International Space Station (ISS) as observed during on-orbit operations of the Robotic External Leak Locator (RELL)
}

\author{
Katie L. Fox*1 ${ }^{*}$ Alexandra M. Deal ${ }^{1}$, Alvin Y. Huang ${ }^{1}$, Michael J. Heiser ${ }^{1}$, \\ William A. Hartman ${ }^{1}$, Ronald R. Mikatarian ${ }^{1}$, Matthew J. Davis ${ }^{1}$ \\ ${ }^{1}$ The Boeing Company, 3700 Bay Area Blvd., Pasadena, TX 77058 \\ Adam J. Naids 2 , Tim A. Bond², Brien Johnson ${ }^{2}$ \\ ${ }^{2}$ NASA Johnson Space Center, 2101 E. NASA Pkwy, Houston, TX 77058 \\ Dino J. Rossetti ${ }^{3}$ \\ ${ }^{3}$ Conceptual Analytics, NASA Goddard Space Flight Center, 8800 Greenbelt Rd., Greenbelt, MD \\ 20771
}

\begin{abstract}
The Robotic External Leak Locator (RELL) was deployed to the International Space Station (ISS) with the goal of detecting and locating on-orbit leaks around the ISS. Three activities to investigate and corroborate the background natural and induced environment of ISS were performed with RELL as part of the on-orbit validation and demonstration conducted in November - December 2016. The first demonstration activity pointed RELL directly in the ram and wake directions for one orbit each. The ram facing measurements showed high partial pressure for mass-to-charge ratio 16, corresponding to atomic oxygen (AO), as well as the presence of mass-to-charge ratio 17. RELL's view in the wake-facing direction included more ISS structure and several Environmental Control and Life Support System (ECLSS) on-orbit vents were detected, including the Carbon Dioxide Removal Assembly (CDRA), Russian segment ECLSS, and Sabatier vents. The second demonstration activity pointed RELL at three faces of the P1 Truss segment. Effluents from ECLSS and European Space Agency (ESA) Columbus module on-orbit vents were detected by RELL. The partial pressures of mass-to-charge ratios 17 and 18 remained consistent with the first on-orbit activity of characterizing the natural environment. The third demonstration activity involved RELL scanning an Active Thermal Control System (ATCS) radiator. Three locations along the radiator were scanned and the angular position of RELL with respect to the radiator was varied. Mass-to-charge ratios 16 and 17 both had upward shifts in partial pressure when pointing toward the Radiator Beam Valve Modules (RBVMs), likely corresponding to a known, small ammonia leak.
\end{abstract}

Keywords: International Space Station, Natural Environment, Spacecraft Charging, Mass Spectrometers

\section{INTRODUCTION}

The United States External Active Thermal Control System (EATCS) on the International Space Station (ISS) uses liquid ammonia $\left(\mathrm{NH}_{3}\right)$ in closed loops to collect, transport, and reject heat. ${ }^{1}$ Detection and location of small ammonia leaks (estimated to be $<50 \mathrm{lbm}$ per day) from the EATCS was identified as a risk by the ISS program and the Robotic External Leak Locator (RELL) was subsequently commissioned to demonstrate the ability to identify and locate small leaks. ${ }^{2}$ Ammonia leaks greater than $50 \mathrm{lbm}$ per day are expected to be detected by visual inspection techniques in combination with system pressure monitoring.

Both the natural environment in Low Earth Orbit (LEO) and the induced environment around ISS must be characterized before results from RELL leak locating activities can be understood. Three separate activities to investigate and understand the natural and induced background environments were performed as part of the RELL on-orbit validation and demonstration conducted November 30 to December 7, 2016. The present work summarizes the background environment scanning activities, provides the total and partial pressure observations measured by RELL, and draws preliminary conclusions about the natural and induced environments around ISS.

*katie.1.fox@ @oeing.com; phone: 1-281-226-4577 
Following the ISS background scanning activities, RELL performed leak locating operations as part of the on-orbit validation and demonstration in November-December 2016. ${ }^{3}$ This included the addition of an extra day of scanning after an ammonia leak was detected. In 2016, the ISS was experiencing an ammonia leak rate of $20.2 \mathrm{lbm}$ per year in the portside EATCS coolant loop; however, the leak rate increased to $101 \mathrm{lbm}$ per year in 2017. Due to the increasing leak rate, the ISS program approved the use of RELL again in February 2017. RELL successfully detected and located a small ammonia leak in the radiator side lines in the port-side EATCS coolant loop. The lines were inspected by a crew member during an Extravehicular Activity (EVA) in March 2017, and the video from the crew member's high definition camera showed small flakes originating from the lines. The lines were then isolated from the port-side EATCS coolant loop in April 2017, and subsequent monitoring of the system pressures indicated that the leak had stopped. The radiator-side EATCS coolant line was retrieved via EVA in March 2018 for inspection on the ground.

\section{METHOD AND BACKGROUND}

\subsection{RELL Development and Instruments}

RELL, shown in Figure 1, is a collaboration between the Goddard Space Flight Center (GSFC) and Johnson Space Center (JSC). RELL consists of two instruments: a cold cathode ion pressure gauge to measure total pressure and a residual gas analyzer (RGA), which is a small mass spectrometer. While both instruments are Commercial Off The Shelf (COTS) hardware, additional design considerations included: 1) thermal management for widely varying environments, 2) structural support during launch, and 3) integration of RELL with ISS systems (e.g. electronics, data processing, and compatibility with ISS robotic arm operations). ${ }^{2}$ RELL testing and assembly was completed at GSFC, including leak detection tests in a thermal vacuum chamber. ${ }^{4}$ Pressure data collected by the RGA was compared with analytical models for a vent/round jet in a rarefied environment. The mass spectrometer was mounted on a translation/rotation stage and moved relative to fixed leak sources near the chamber wall. The testing simulated leak rates from $1 \mathrm{lbm}$ per year to $1 \mathrm{lbm}$ per day of a mixture of ammonia and water. The analysis results on the distance squared dependence and cosine relationship between the leak source and pointing vector of the RGA showed that the models successfully predicted measured plume behavior.

A second RELL flight unit was launched pressurized as a Technology Demonstration Payload in December 2015 on Orbital-ATK Commercial Resupply Flight 4 (CRS-4) after the first flight unit was lost in the Orbital-ATK CRS-3 launch failure. RELL was stowed inside the ISS until the on-orbit demonstration in November 2016. It was loaded on the Japanese Experiment Module (JEM) airlock slide table and connected to the Space Station Remote Manipulator System (SSRMS) via the Special Purpose Dexterous Manipulator (SPDM) robotic arm after moving through the airlock.

The RGA-100 from Stanford Research Systems (Sunnyvale, CA) is a typical quadrupole gas analyzer that measures for a mass range from 1 to 100 ion mass-to-charge ratios, or approximately, atomic mass units (amu). The RGA has three main sections: 1) electron impact ion source, 2) quadrupole ion filter, and 3) an ion detector..$^{5-6}$ The ion source produces positive ions by bombarding gas molecules with electrons from a heated filament. The ions are directed toward the quadrupole filter where they are separated by their mass-to-charge ratio. A combination of Direct Current (DC) and Radio Frequency (RF) voltages are applied to the quadrupole rods, increasing the probability of ions with certain mass-to-charge ratios to travel down the axis of the filter towards the detector. The probability of other ions reaching the detector is much smaller. These ions are deflected to the cylindrical rods or surrounding structure. The Faraday Cup detector measures current directly and for increased sensitivity, an electron multiplier measures the electron current proportional to the ion current. The Faraday Cup and the electron multiplier gives the RGA the capability of measuring pressures between $10^{-15}$ to $10^{-5}$ Torr. Scan times can vary from several seconds to a minute based on the parameters set by the user (e.g., mass range). The low range of mass-to-charge ratio (1 to 100) means RELL is not a reliable tool for quantifying materials outgassing from ISS system hardware, external payloads, or visiting vehicles.

The PKR251 ion pressure gauge from Pfeiffer Vacuum Inc. (Nashua, NH) is a combination of a Pirani gauge and a cold cathode system. ${ }^{7}$ A tungsten filament in the PKR251 Pirani gauge is heated when a current flows through it. Gas molecules' collisions with the filament remove heat from it. The pressure of the surrounding environment can be determined from this heat dissipation rate. The cold cathode system utilizes orthogonal electric and magnetic fields to trap electrons. Electrons are drawn from the cathode to a potential field and deflected by the magnetic field, causing them to spiral around the anode. The spiraling increases the opportunity to collide and ionize gas molecules. The ions are captured by an ion collector generating a current proportional to the gas density. The measurement range for the ion gauge is $10^{-9}$ to 1 Torr. Response times range from $\sim 10 \mathrm{~ms}$ for pressures above $7.50 \times 10^{-7}$ Torr to $\sim 1 \mathrm{~s}$ for pressures at the low end of the range. The ISS has previously flown this ion pressure gauge on the Materials Degradation and Exposure Experiment (MEDET) from February 
2008 to September 2009 as part of the Columbus module payload European Technology Exposure Facility (EuTEF). ${ }^{8}$ Russian scientists also made various pressure measurements during thruster firings and vents for the ASTRA-II experiment on the MIR Space Station. ${ }^{9}$

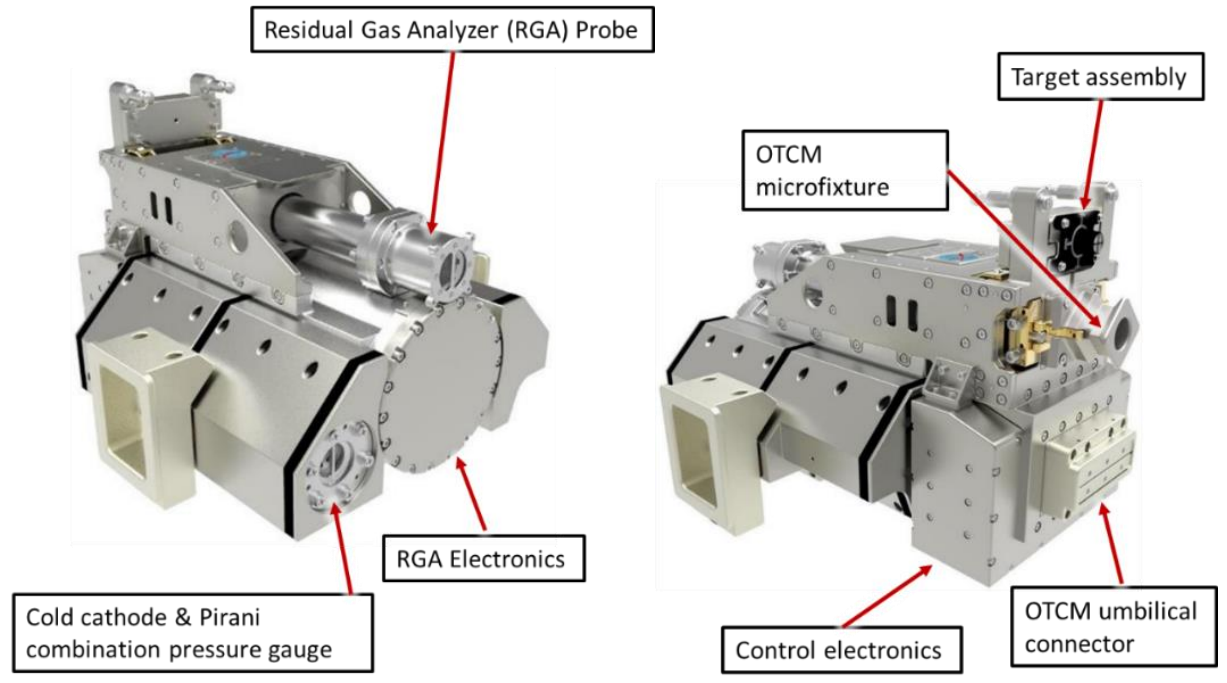

Figure 1: Robotic External Leak Locator (RELL) instruments

\subsection{ISS Environmental Control and Life Support Systems (ECLSS)}

The contribution of the venting activities of the Environmental Control and Life Support Systems (ECLSS), comprising of life support systems hardware on the Russian Segment and the United States Operating Segment (USOS), to the induced ISS environment was observed by RELL. There are two main ECLSS operating on the USOS: 1) in Node 3, and 2) in the U.S. Laboratory. Node 3's Regenerative ECLSS comprises of the Carbon Dioxide Removal Assembly (CDRA), the Oxygen Generation Assembly (OGA), the Sabatier Assembly, and Water Recovery System. The primary gaseous byproducts to be vented overboard from the ECLSS are: carbon dioxide $\left(\mathrm{CO}_{2}\right)$ and hydrogen $(\mathrm{H} 2) .{ }^{10}$ The Sabatier on occasion converts carbon dioxide (from the CDRA) and hydrogen (from the OGA) to methane $\left(\mathrm{CH}_{4}\right.$ ) and water $\left(\mathrm{H}_{2} \mathrm{O}\right.$ ). The $\mathrm{CO}_{2}$ is held in the CDRA bed until the Sabatier makes a demand for it. Node 3 has three single vent lines: 1) $\mathrm{CO}_{2}, 2$ ) $\mathrm{H}_{2}$, and 3) Air. When the Sabatier is operational, the system vents $\mathrm{CO}_{2}$ and $\mathrm{CH}_{4}$ from the $\mathrm{CO}_{2}$ vent line and $\mathrm{H}_{2}$ from the $\mathrm{H}_{2}$ vent line. The air vent line is only used at the startup. The U.S. Laboratory also has all of the Node 3 ECLSS components except for the Sabatier Assembly. Both of the Node 3 and U.S. Laboratory systems usually operate with a 144 minute cycle. The vent for the U.S. Laboratory CDRA is a non-propulsive one (i.e. T-vent) in comparison to the Node 3 single vent lines. The Sabatier was removed from the ISS in late 2017 and returned back to the ground.

On the Russian segment, there are two continuous vents, Vozdukh and Elektron, on the Service Module (SM). Similar gas byproducts are generated except for water which is recovered in the USOS. The Vozdukh has six exit holes comprising the vent and the Elektron has four exit holes. The Vozdukh releases primarily carbon dioxide in conjunction with air and water. The Elektron provides oxygen to the ISS and vents hydrogen in additional to water as the system on the Russian segment does not recover the water. Depending on the operating mode, the cycle time may be 10, 20, or 30 minutes.

The observations of ISS ELCSS venting will be discussed here in the context of the overall RELL natural and induced environment background scans. Additional details of the ECLSS vent effluents measured by RELL and their reflection off ISS system hardware, particularly of the carbon dioxide vented from Node 3, are available. ${ }^{11}$

\subsection{Thermosphere and Ionosphere Environments}

The International Space Station orbits the Earth at an altitude of approximately $400 \mathrm{~km}$. This places the ISS in the thermosphere, where the dominate species is atomic oxygen $(\mathrm{O})$, followed by molecular nitrogen $\left(\mathrm{N}_{2}\right)$. The abundance of atomic oxygen is due to the photodissociation of molecular oxygen $\left(\mathrm{O}_{2}\right)$ by solar UV radiation coupled with the absence of turbulent mixing above the turbopause (approximately $100 \mathrm{~km}$ ) and the slow recombination rate of atomic oxygen. ${ }^{12-13}$ Solar UV radiation drives changes in the thermosphere, including diurnal effects where the diurnal temperature variation is almost $30 \%$, along with latitudinal and seasonal effects. 
Due to the low pressure at the high altitudes (above approximately $100 \mathrm{~km}$ ), the ionized species do not necessarily recombine quickly, resulting in a permanent population of ions and free electrons. The concentration of electrons is approximately $1 \%$ of the neutral concentration. ${ }^{14}$ This ionosphere overlaps the mesosphere, thermosphere, and exosphere and is electrically conducting.

\subsection{RELL Environment Characterization Scanning Activities}

Three different scanning activities were developed to fulfill the on-orbit demonstration objective of characterizing the natural and induced environment around ISS. The first demonstration activity (Background Scanning A) pointed RELL directly in the ram $(+\mathrm{X})$ and wake $(-\mathrm{X})$ directions at the zenith-most point of ISS reachable by the SSRMS for one orbit each. This was done to capture as pristine an environment as possible to understand diurnal effects in Low Earth Orbit (LEO) and characterize the ISS natural environment, including atomic oxygen (AO) effects.

A hemispherical view of the ram-facing scanning direction is shown in the left hemispherical view of Figure 2, which shows no structure is visible within $60^{\circ}$ of the RELL centerline. A hemispherical view of the wake-facing scanning direction is shown in the right portion of Figure 2, which shows there is significantly more ISS structure in the field of view, including the Russian segment. This structure interfered with the ability of RELL to accurately characterize the natural environment in the wake $(-X)$ direction, notwithstanding the interference of the environment induced by several ECLSS vents.

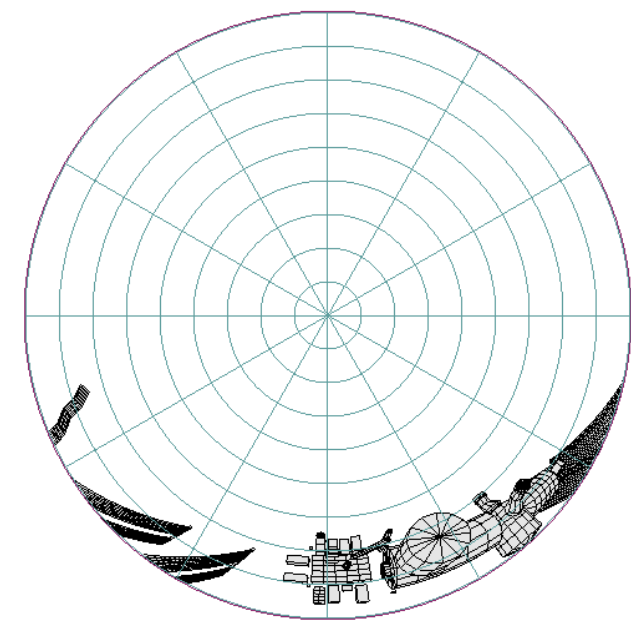

(a)

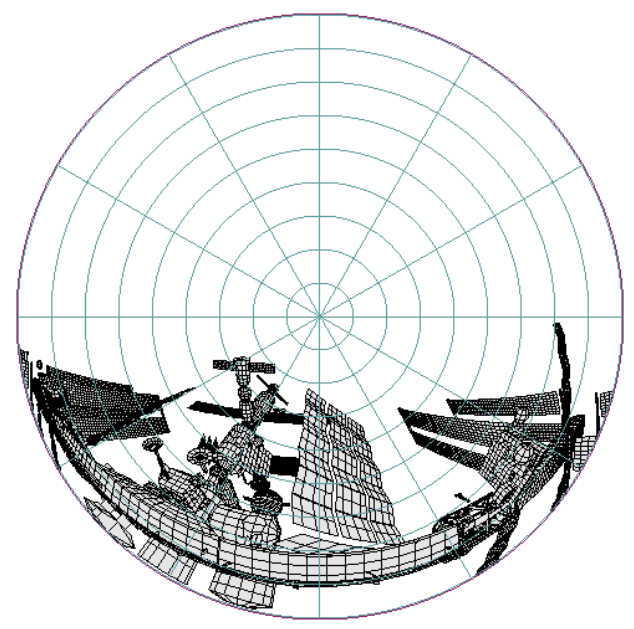

(b)

Figure 2: Hemispherical view of (a) ram-facing and (b) wake-facing background scan locations.

The second demonstration activity (Background Scanning B) pointed RELL at several faces of the P1 Truss with the objective of understanding the ISS truss induced environment. Of particular interest was the level of atomic oxygen reflected off the truss structure. The National Institute of Standards and Technology (NIST) mass spectra of ammonia $\left(\mathrm{NH}_{3}\right)$ is shown in Figure $3^{15}$ and the relative intensity of mass-to-charge ratio of 16 is very high relative to the dominant mass-to-charge ratio of 17. Atomic oxygen by definition has a mass-to-charge ratio of 16 and therefore could interfere with the interpretation of RELL measurements of ammonia. The area of interest on the truss is highlighted in Figure $4,{ }^{16}$ and hemispherical views of the scanning locations are shown in Figure 5. At each face, the angular position of RELL was varied $22.5^{\circ}$ and $45^{\circ}$ in both the starboard (+Y) and port (-Y) directions from the normal direction to the face being scanned. A schematic of the angular measurement positions for Face 1 is shown in Figure 6. 
Ammonia

Mass Spectrum

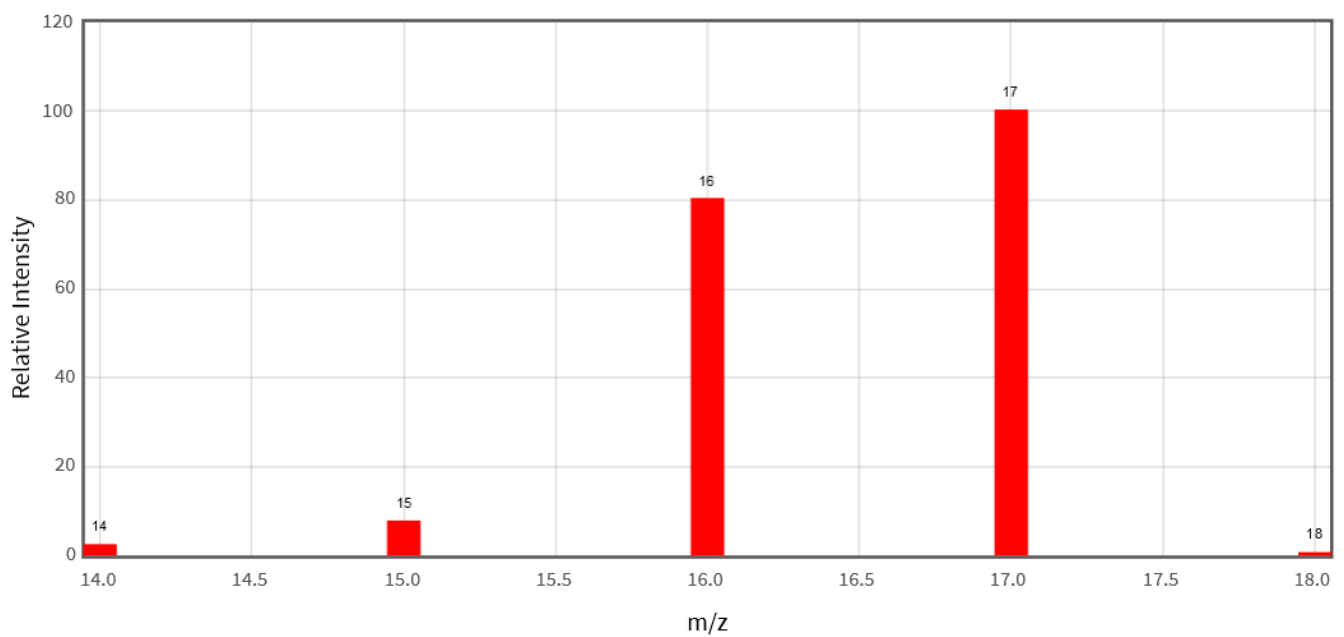

Figure 3: NIST Mass Spectra for Ammonia $\left(\mathrm{NH}_{3}\right)$

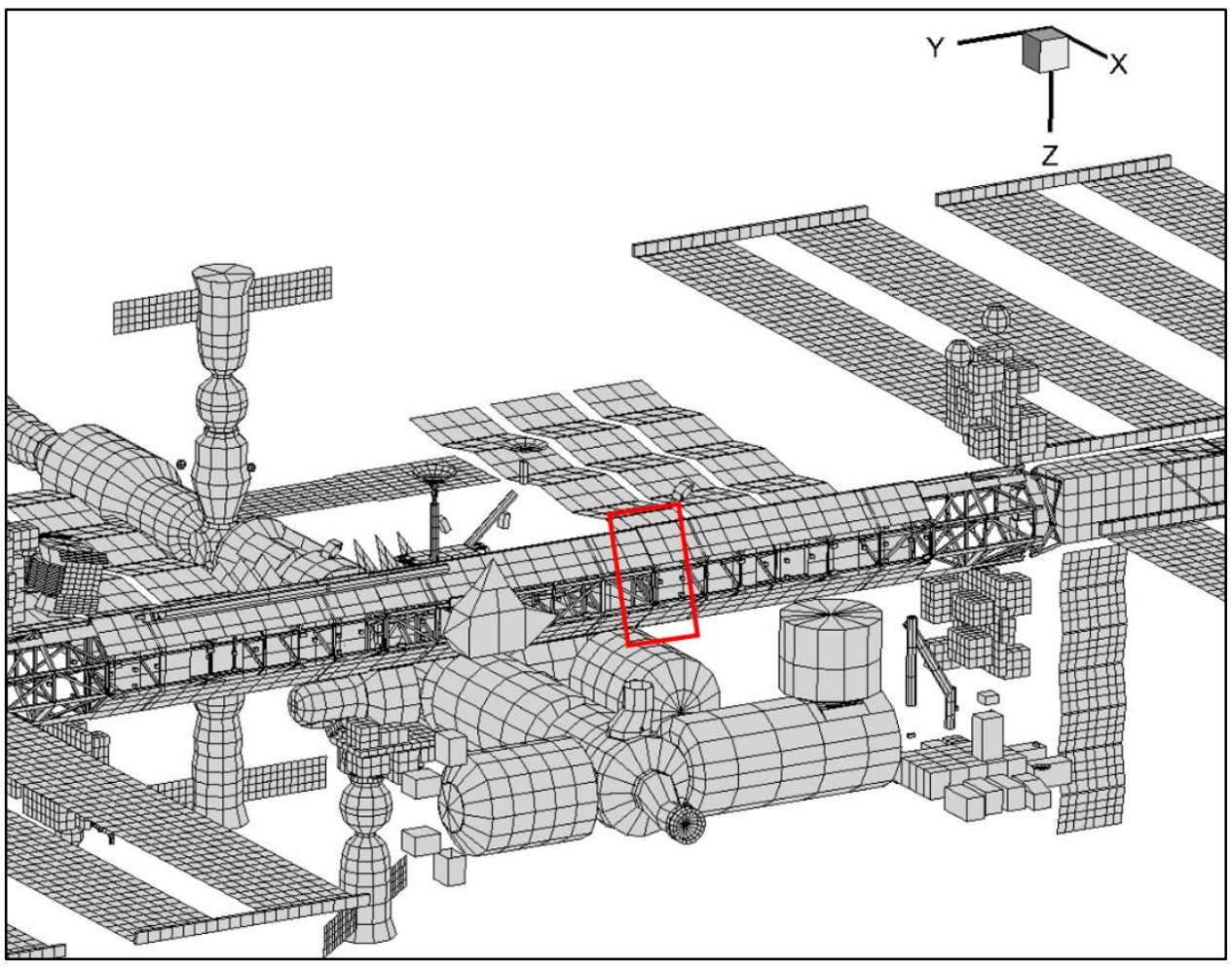

Figure 4: ISS P1 Truss scanning area 


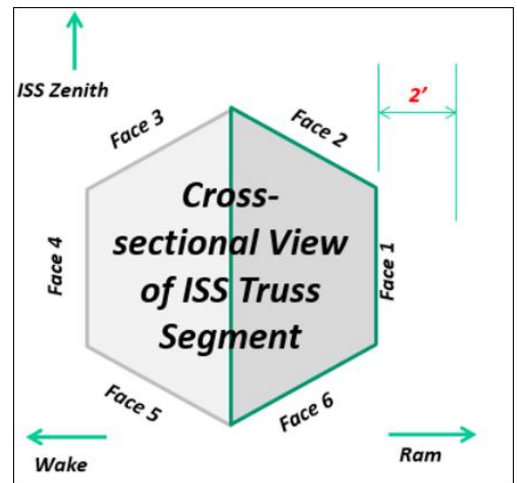

(a)

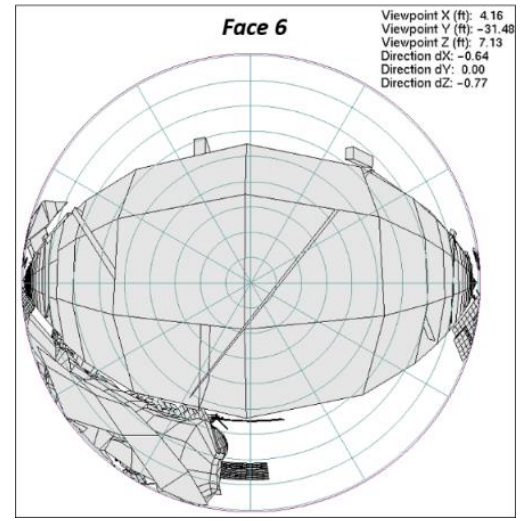

(c)

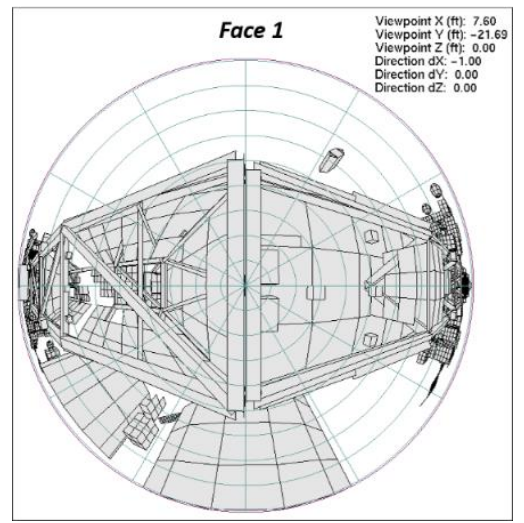

(b)

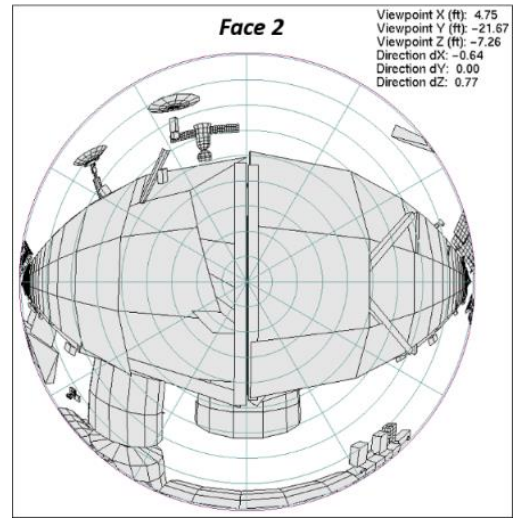

(d)

Figure 5: (a) Schematic of P1 Truss segment cross-section and (b, c, d) hemispherical views of each scanned face.

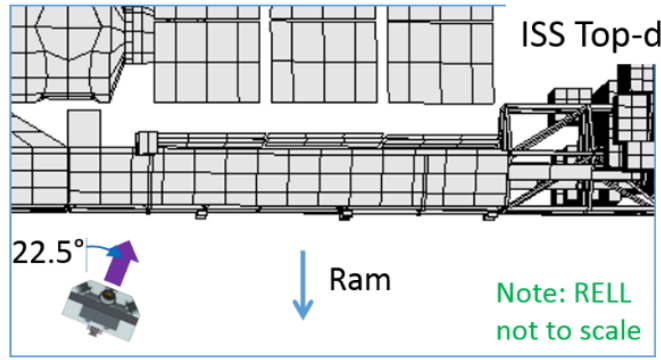

Measurement 2: Rotate the RELL $22.5^{\circ}$ in the port/outboard direction $(-Y)$ maintaining 2 feet clearance from Face 1

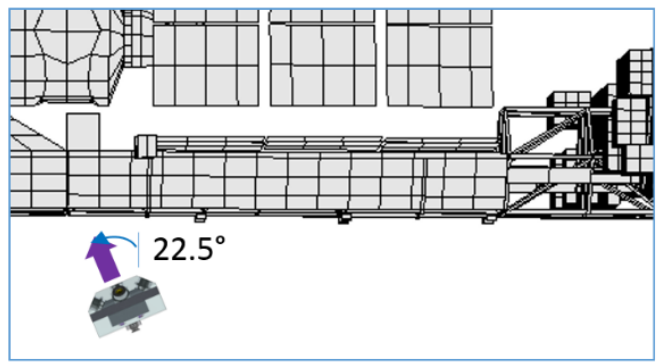

Measurement 4: Rotate the RELL $22.5^{\circ}$ in the starboard/inboard direction $(+Y)$ maintaining 2 feet clearance from Face 1

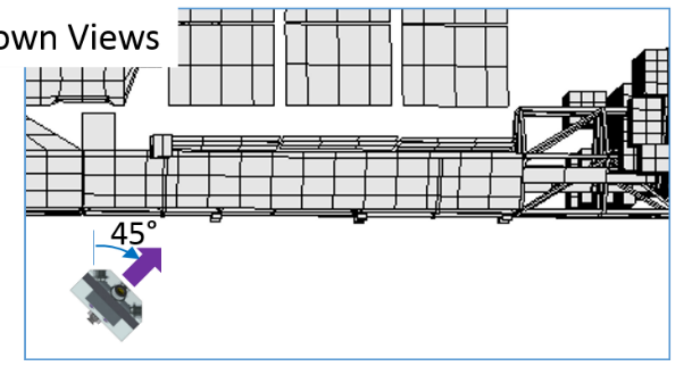

Measurement 3: Rotate the RELL another $22.5^{\circ}$ in the port/outboard direction $(-Y)$ maintaining 2 feet clearance from Face 1

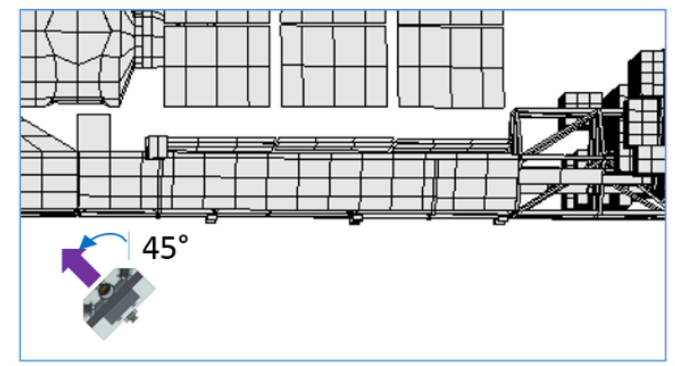

Measurement 5: Rotate RELL another $22.5^{\circ}$ in the starboard/inboard direction $(+Y)$ maintaining 2 feet clearance from Face 1

Figure 6: Schematic of RELL measurement positions and rotations from P1 Truss Face 1 scanning position. 
The third demonstration activity (Background Scanning C) involved RELL scanning the ISS External Active Thermal Control System (EATCS) radiators with the goal of understanding the radiator induced environment. Since the primary purpose of RELL is to locate EATCS ammonia leaks, it was important to understand if the radiator induced environment already contains high levels of the major ammonia mass-to-charge ratios (16 and 17). This is to help prevent the identification of EATCS ammonia leaks where none actually exist by characterizing the environment around the EATCS. Three locations along the second port-side EATCS radiator, highlighted in Figure 7, were scanned: 1) at the base, 2) 8 feet from the base, and 3) 16 feet from the base. The angular position of RELL was also varied $22.5^{\circ}$ and $45^{\circ}$ from true nadir $(+Z)$ in both the ram $(+X)$ and wake $(-X)$ directions. A schematic of the angular measurement positions is shown in Figure 8 and hemispherical views of the scanning locations are shown in Figures 9, 10, and 11.

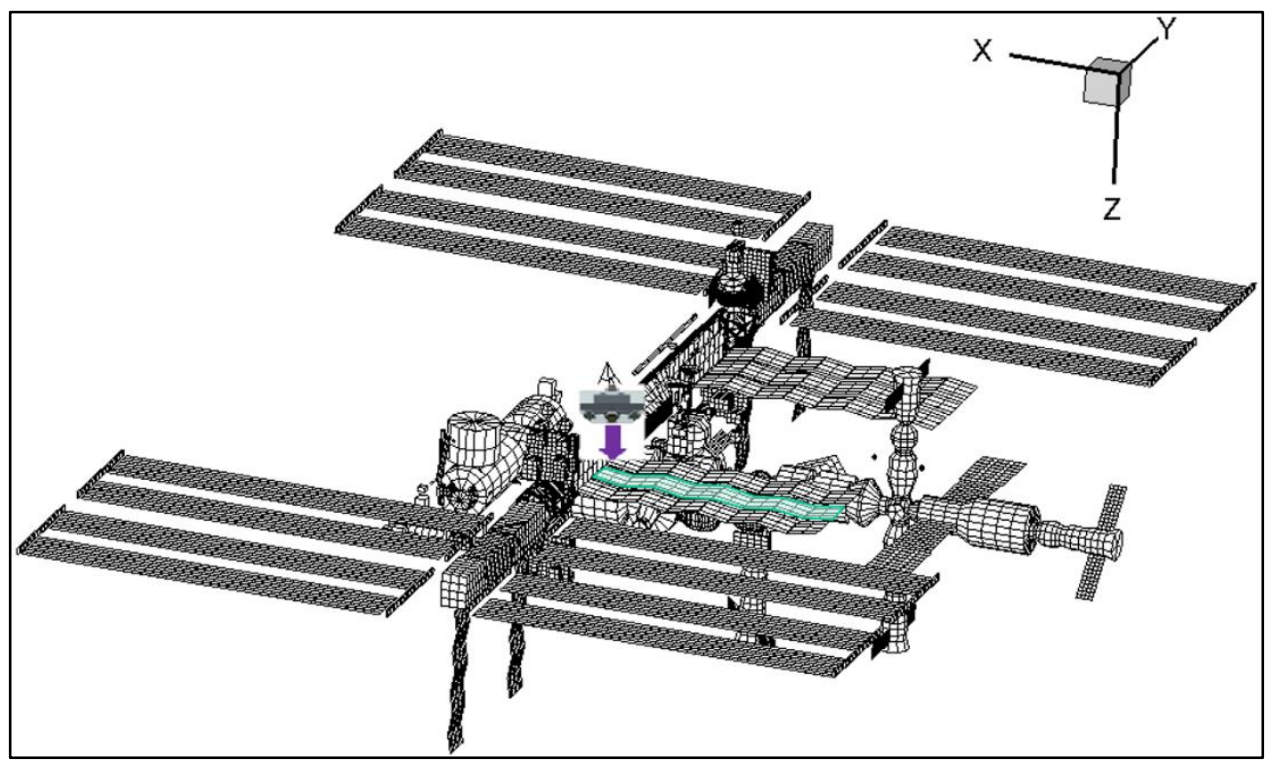

Figure 7: Schematic of RELL position over second port side EATCS radiator (highlighted)

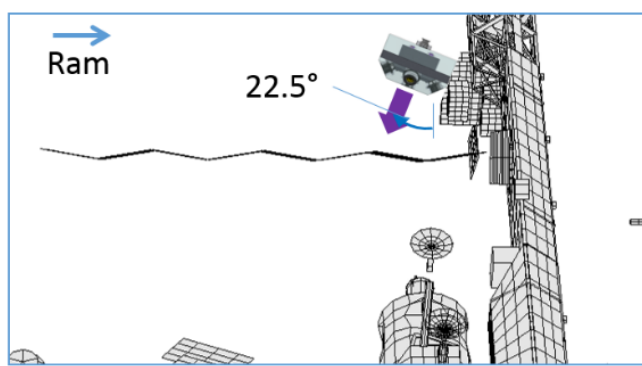

Measurement 2: Rotate the RELL $22.5^{\circ}$ along the length of the radiator towards ISS wake direction $(-X)$ maintaining $2 \mathrm{ft}$ clearance

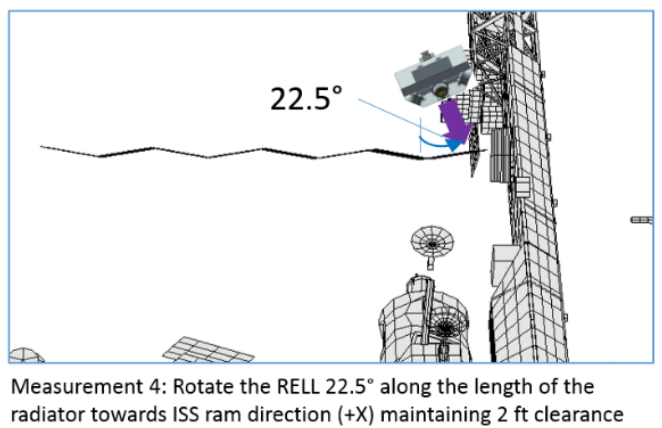

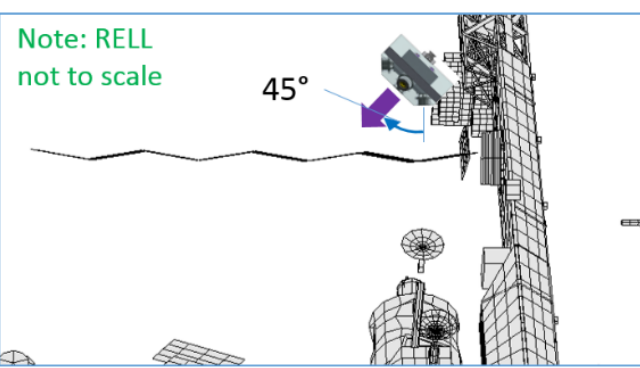

Measurement 3: Rotate the RELL another $22.5^{\circ}$ along the length of the radiator towards ISS wake direction $(-\mathrm{X})$ maintaining $2 \mathrm{ft}$ clearance

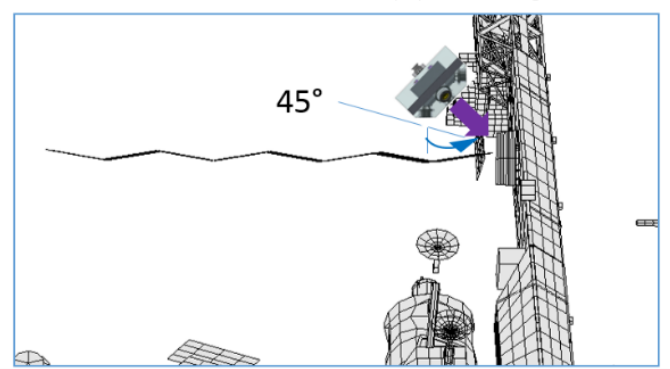

Measurement 5: Rotate the RELL another $22.5^{\circ}$ along the length of the radiator towards ISS ram direction $(+\mathrm{X})$ maintaining $2 \mathrm{ft}$ clearance

Figure 8: Schematic of RELL measurement positions as rotations from nadir pointing direction above second port-side EATCS radiator 


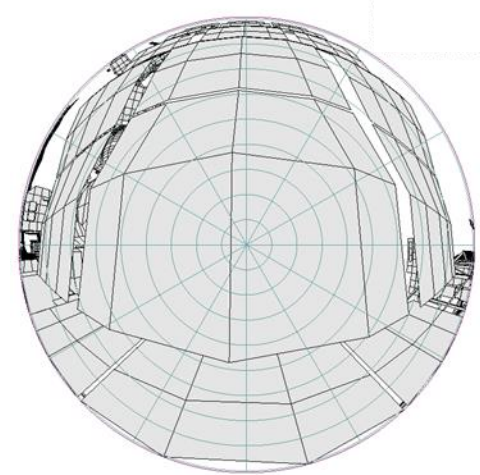

(a)

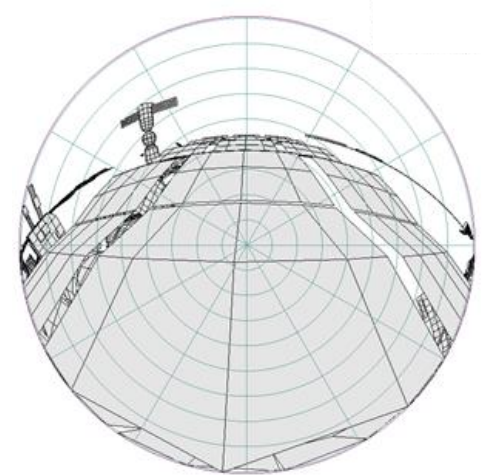

(b)

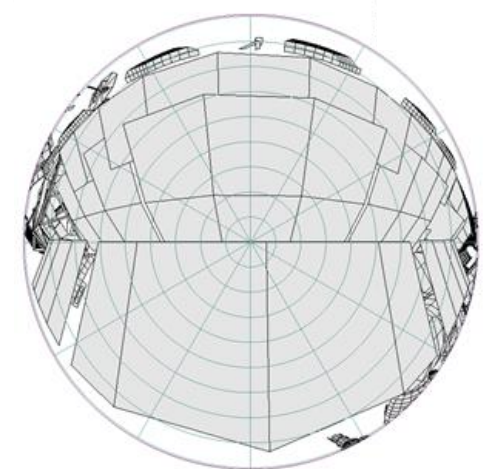

(c)

Figure 9: Hemispherical views at base of second port-side EATCS radiator: (a) pointing directly nadir $(+Z)$, (b) rotated $45^{\circ}$ in wake direction $(-\mathrm{X})$ from nadir, and (c) rotated $45^{\circ}$ in ram direction $(+\mathrm{X})$ from nadir.

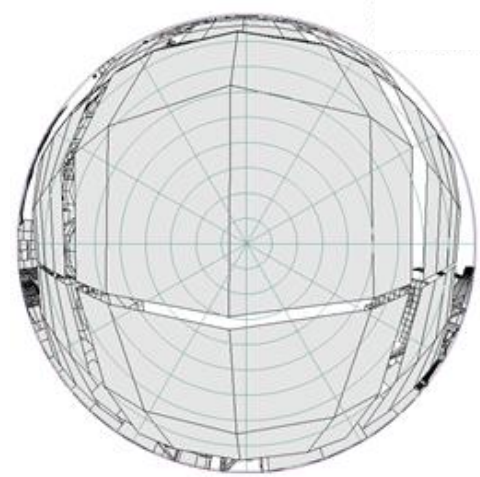

(a)

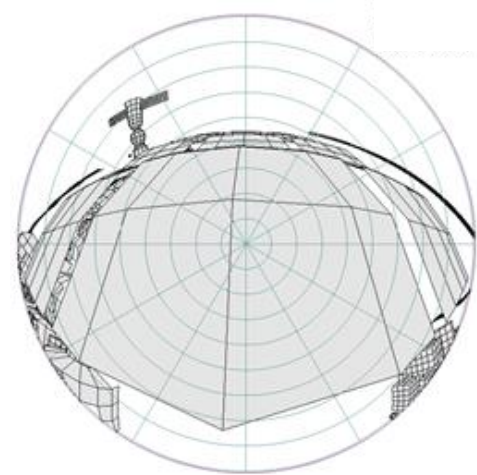

(b)

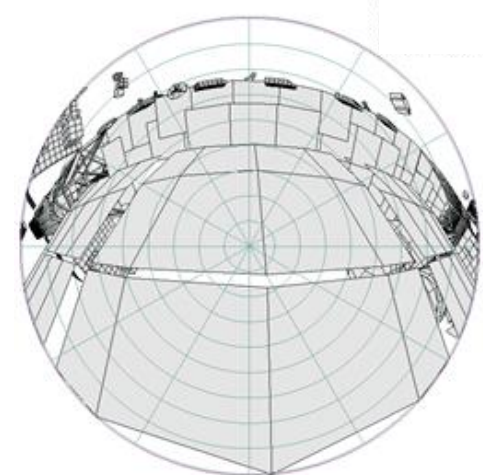

(c)

Figure 10: Hemispherical views at 8 feet from base of second port-side EATCS radiator: (a) pointing directly nadir $(+Z)$, (b) rotated $45^{\circ}$ in wake direction $(-\mathrm{X})$ from nadir, and (c) rotated $45^{\circ}$ in ram direction $(+\mathrm{X})$ from nadir.

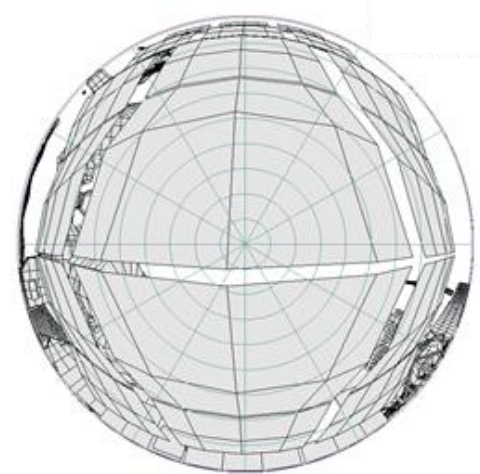

(a)

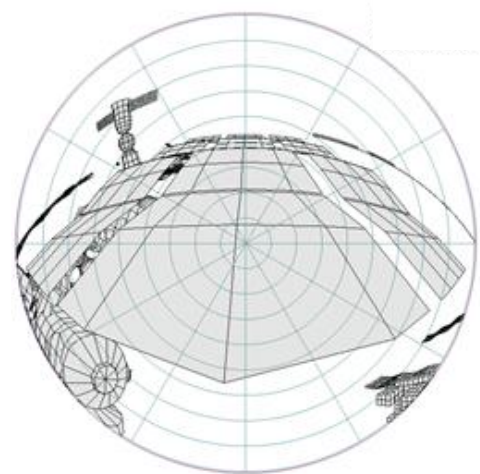

(b)

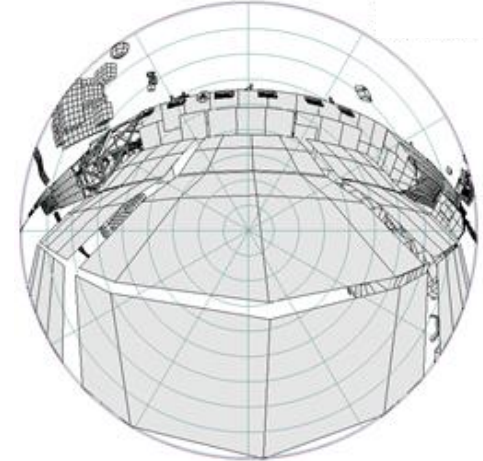

(c)

Figure 11: Hemispherical views at 16 feet from base of second port-side EATCS radiator: (a) pointing directly nadir $(+Z)$, (b) rotated $45^{\circ}$ in wake direction $(-\mathrm{X})$ from nadir, and (c) rotated $45^{\circ}$ in ram direction $(+\mathrm{X})$ from nadir. 


\subsection{RELL RGA Measurement of Water and Ammonia}

One of the critical parameters in recognizing an ammonia signature from the RGA data is evaluating the ion mass-tocharge ratios of 16 and 17 . The natural environment contributes $16 \mathrm{O}$ and $17 \mathrm{O}$ isotopes in addition to water, whether from materials or recondensation when stowed in the ISS cabin. The number density of 170 is expected to be several orders of magnitude below that of 160 based on the NRLMSISE-00 atmosphere model. ${ }^{16}$

Unfortunately, the recondensed water due to internal ISS stowage affected both sets of RGA measurements of the natural environments, as the ram position measurements were completed in the beginning of both the 2016 and 2017 RELL operations. Figures 3 and 12 provide the NIST mass spectra for ammonia $\left(\mathrm{NH}_{3}\right)$ and water $\left(\mathrm{H}_{2} \mathrm{O}\right)$, respectively. Comparison of the ion mass ratios of 16 to 17 for ammonia and water provides important information to distinguish ammonia from water. The ion mass ratios of 16 to 17 for ammonia and water are 0.8 and 0.04 , respectively. Figure 13 shows the difference in on-orbit mass spectra measured by the RGA used for detection of water and ammonia, respectively. The increase in the ion mass 16 peak in comparison to ion mass 17 peak, in addition to total pressure increase, indicates the presence of ammonia.

Prior to beginning the February 2017 operations, this water bake-off took approximately 12 to 14 hours after RELL was turned on outside the ISS. Stowing RELL externally, rather than inside the ISS, would avoid the need for a water bake-off in the future.

Water

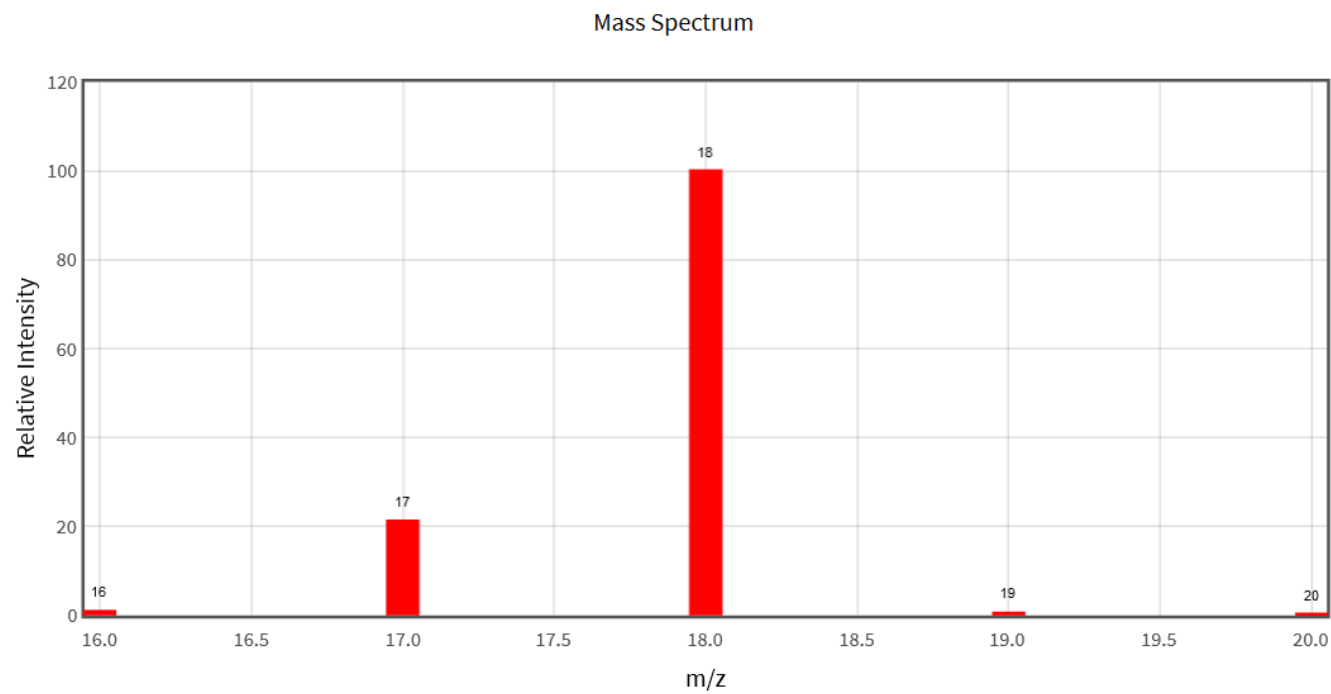

Figure 12: NIST Mass Spectra of Water $\left(\mathrm{H}_{2} \mathrm{O}\right)$

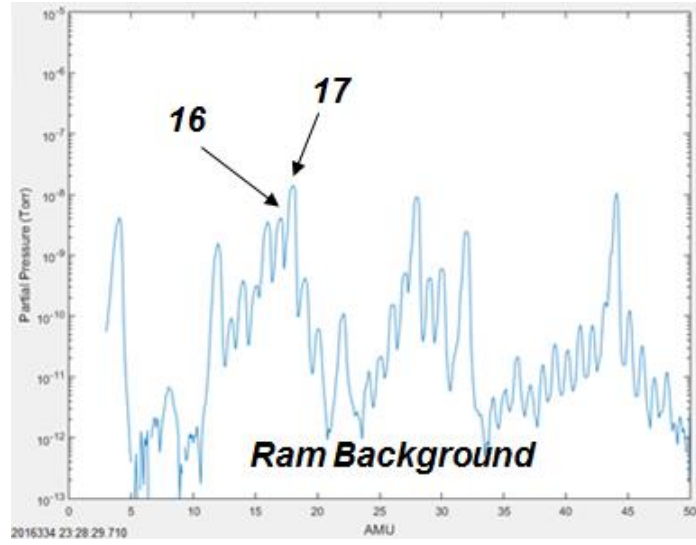

(a)

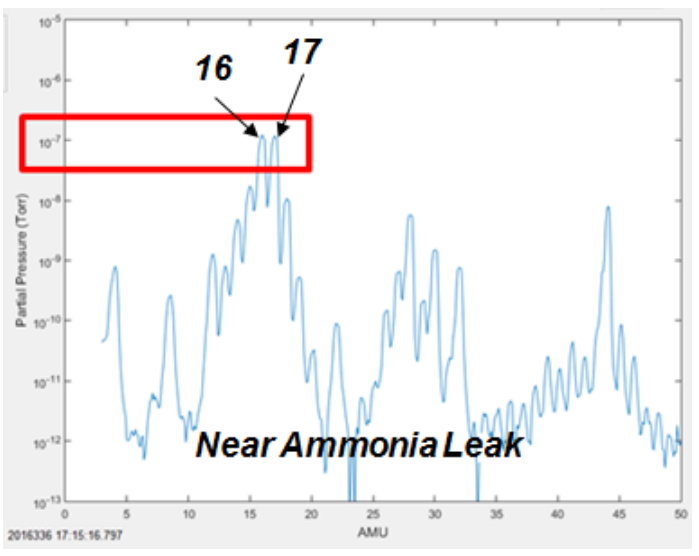

(b)

Figure 13: (a) Water effect on Ram RGA on-orbit measurements and (b) RGA measurements near ammonia leak 


\section{RESULTS AND DISCUSSION}

\subsection{Background Scanning A}

The goal of the first background scanning activity was to scan as pristine an environment as possible in both the ram $(+\mathrm{X})$ and wake (-X) positions (see Figure 2). The background scans were also the first scans of RELL at ISS, and both the ion gauge and RGA instruments performed well.

The total pressure measured by the ion gauge is compared with the sum of partial pressures measured by the RGA over the mass-to-charge range of 3 to 50 in Figure 14. The period of insolation is also shown for reference (yellow $=$ in sun, black $=$ in eclipse). The 'bump' in the sum of partial pressures at eclipse exit is a result of a similar bump in several individual partial pressures. Partial pressure results for the most prevalent constituents in the ram facing scans are shown in Figure 15. When pointing in the ram direction, the most prevalent species was expected to be atomic oxygen (mass-tocharge ratio of 16) and the RGA did measure atomic oxygen as having one of the highest partial pressure values. The 'bump' shape of the summed partial pressures in Figure 12 is dominated by the atomic oxygen (mass-to-charge ratio of 16), followed by mass-to-charge ratios of 14 and 15 . The other major constituent expected in the natural environment of the thermosphere is molecular nitrogen $\left(\mathrm{N}_{2}\right)$, and this is confirmed by the high level of mass-to-charge ratio of 28 . Data from the MSISE-00 atmospheric model ${ }^{16}$ over the period of ram-facing scanning activities was compared with the on-orbit RGA measurements. The partial pressures of mass-to-charge ratios 16, 17, and 18 are compared to MSISE-00 predictions of atomic oxygen $(\mathrm{O})$ and anomalous oxygen in Figure 16(a) and the partial pressure of mass-to-charge ratio 28 is compared to MSISE-00 predictions of nitrogen $\left(\mathrm{N}_{2}\right)$ in Figure 16(b). The MSISE-00 pressures include the dynamic pressure component, assuming the ISS velocity is $7600 \mathrm{~m} / \mathrm{s}$. Not including the 'bump' of mass-to-charge ratio 16, the shape of the measured partial pressures are the same as the shape of the predicted constituent partial pressures. The partial pressures of both mass-to-charge ratio 16 and 28 are lower than the predicted levels of atomic oxygen and nitrogen, respectively.

Relevant to ammonia leak locating efforts, the background level of mass-to-charge ratio of 17 is 6.04E-09 torr. Oxygen17 and oxygen-18 are present in the environment, with partial pressure levels of mass-to-charge ratios of 17 and 18 in the same range of atomic oxygen. The mass spectrum of water $\left(\mathrm{H}_{2} \mathrm{O}\right)$ also includes mass-to-charge ratio of 17 with an expected ion mass ratio of 0.20 compared to mass-to-charge ratio of 18. In the pressure measurements in Figure 14, and slightly less so in the partial pressure measurements in Figure 15, the diurnal effect is seen. This effect is partially due to solar UV radiation.

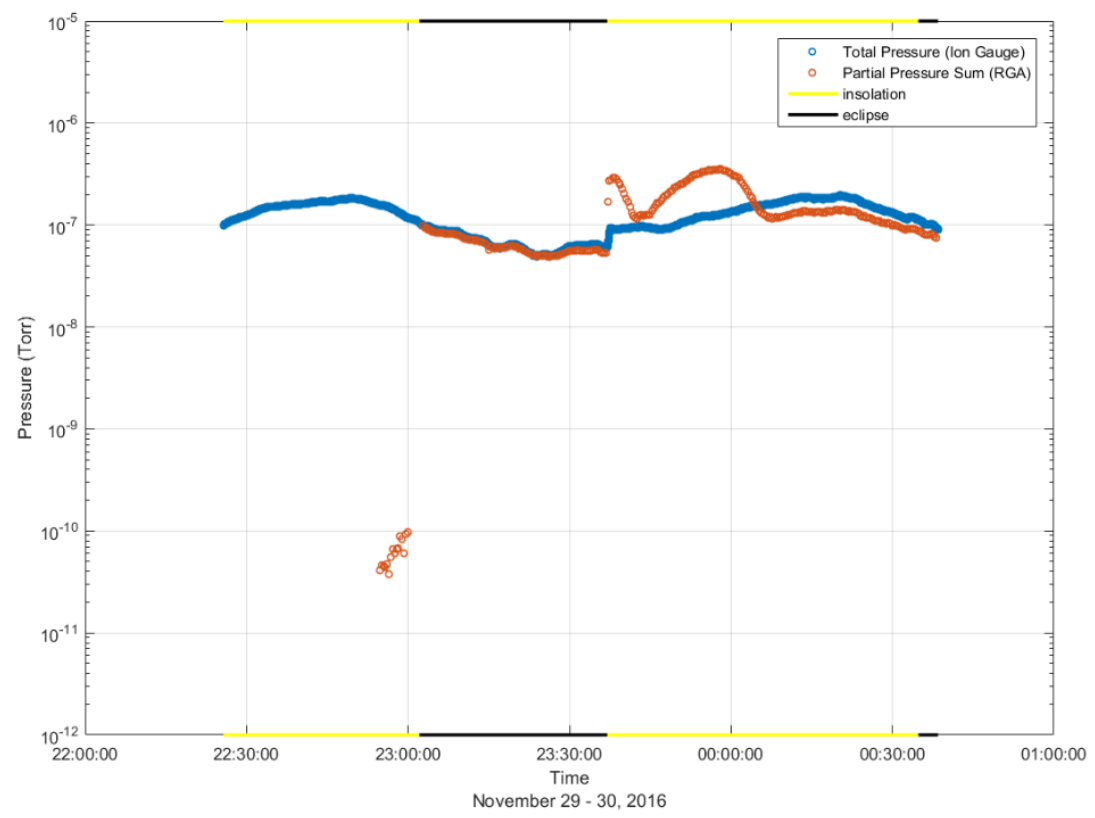

Figure 14: Total pressure and sum of partial pressure range (amu 3 to 50) measured by RELL in the ram (+X) scanning position. 


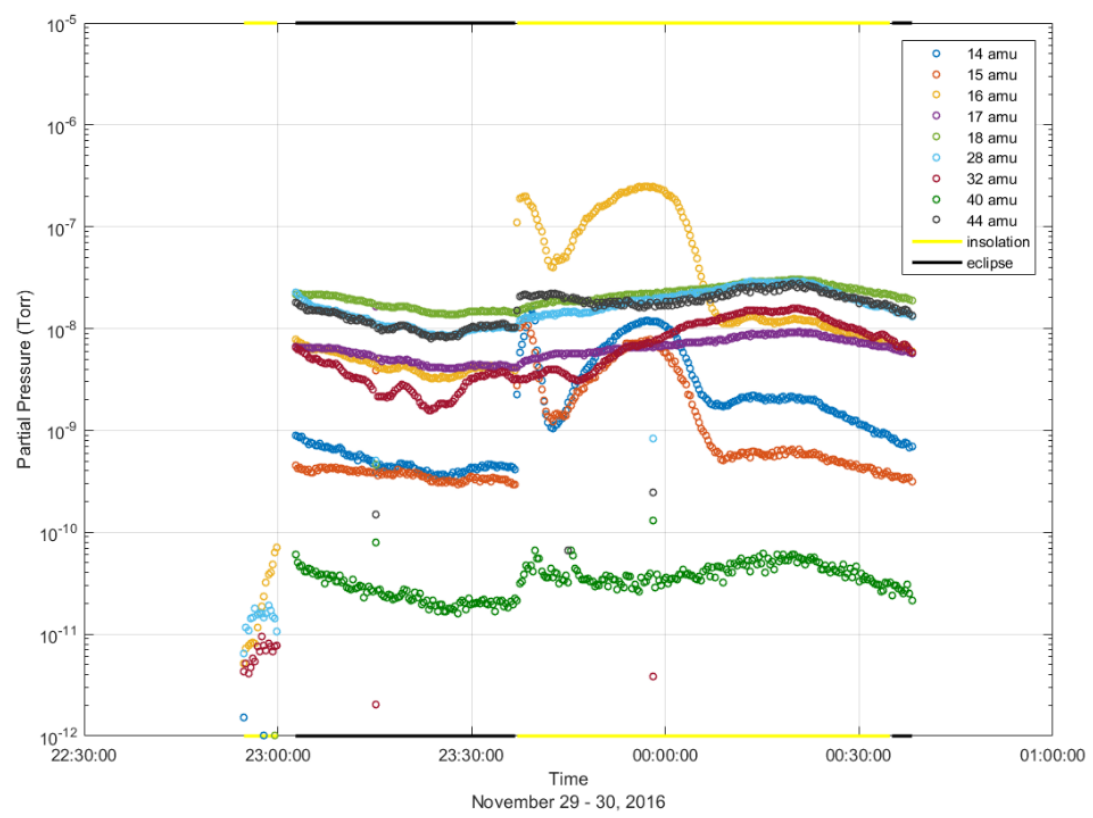

Figure 15: Selected partial pressures measured by the RGA in the ram $(+\mathrm{X})$ scanning position.

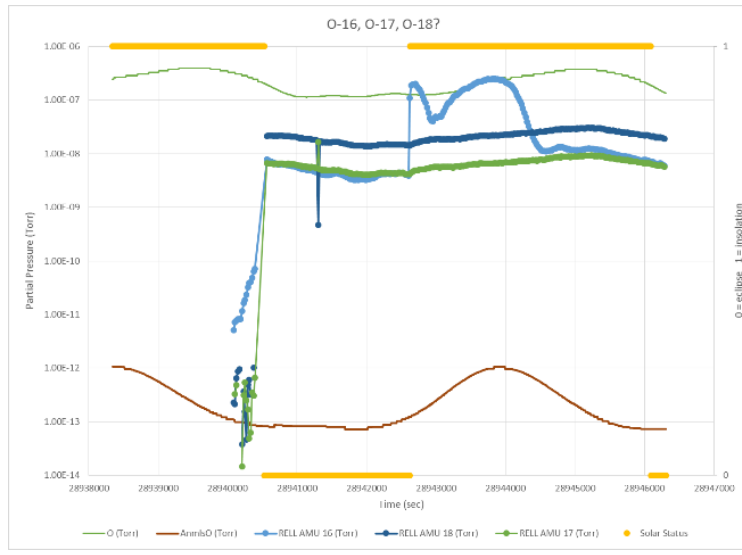

(a)

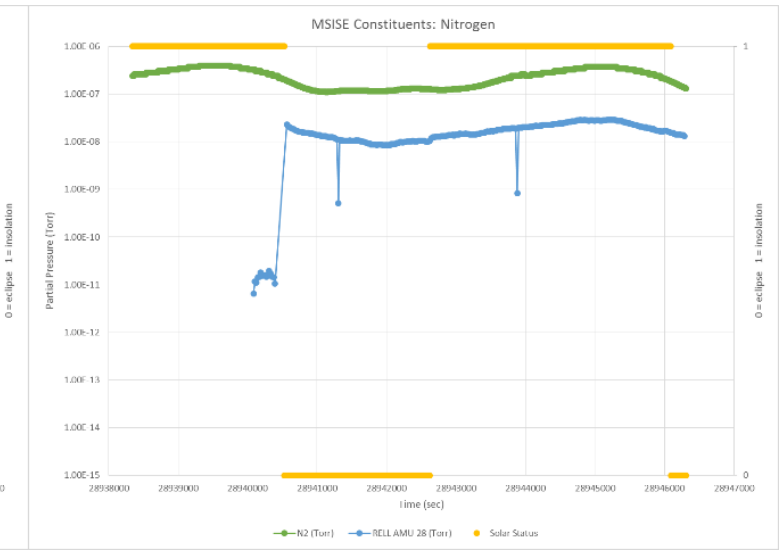

(b)

Figure 16: Comparison of MSISE-00 atmospheric model data with RGA on-orbit measurements.

The 'bump' in partial pressures corresponding to mass-to-charge ratios of 14, 15, and 16 - among others - is not believed to be a realistic feature of the background environment. The RGA probe operates by ionizing a small fraction of the gas molecules in the environment. The ions are then separated and detected by measuring the ions' current, which gives a measure of the molecular mass (mass-to-charge ratio). The bump shape of the RGA data is strong evidence that the current measured by the RGA's ion detector was affected by the negative ISS floating potential. In the thermosphere environment in which the ISS flies, approximately $1 \%$ of the gases are ionized and the electrons are much more mobile than the ions. The electrons are attracted toward the ISS solar arrays, and the charge (i.e. floating potential) of the ISS is driven negative until the current from the ions and the electrons are equal. Figure 17 is an example of the voltage measurement from the ISS Floating Potential Measurement Unit (FPMU). The black and gold color at the top and bottom of the plot correspond to periods of eclipse and insolation, respectively. 


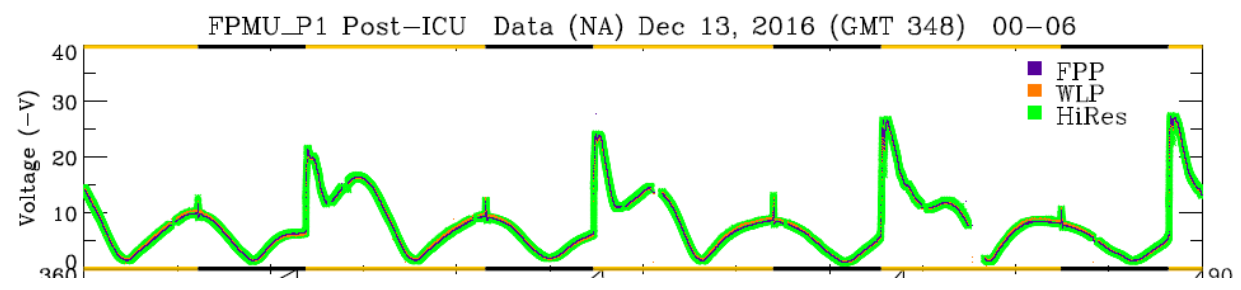

Figure 17: Example ISS Floating Potential Measurement Unit (FPMU) voltage plot

The largest ISS charging is generally seen at eclipse exit due to the effect of solar UV radiation. The ISS floating potential is also highly affected by the geomagnetic field and therefore the latitude of ISS affects its floating potential. At high latitudes there can be a significant voltage drop in the plasma along the ISS truss, which can cause a broad peak in the floating potential measurements. The RGA instrument is grounded to ISS and when ISS has a negative floating potential the positive ions around ISS are accelerated into the instrument. These positive ions (e.g., AO+) are in addition to the neutral gas molecules that are ionized by the RGA instrument ionizer, so the measured current of atomic oxygen, among others, increases as the ISS floating potential becomes more negative. This leads to higher, and inaccurate, measurements of these constituents. The two features of the 'bump' in the RGA data correspond to the highest charging levels at eclipse exit and the significant voltage drop at high latitudes seen in the FPMU data.

The wake-facing background scans eliminated the interference of the ISS floating potential, but introduced another new complexity due to the amount of ISS structure in RELL's field of view during the wake background scan: detection of ISS vents (see Figure 3). ${ }^{11}$ The total pressure measured by the ion gauge and the sum of partial pressures measured by the RGA are shown in Figure 18.

The periodic nature of the measured pressure spikes in Figure 18 suggests that RELL is detecting effluents from nominal ISS ECLSS vents. The smaller pressure peaks occurring every 20 minutes (six total are shown in Figure 18) correspond to nominal venting of the Russian segment ECLSS. The dip in pressure midway through the scan also begins rapidly and returns to the 'baseline' pressure shortly afterwards, which also suggests a vent as opposed to a continuous leak. This dip corresponds to the nominal venting of the Sabatier water production system on Node 3. The large peak towards the end of the scanning activity corresponds to the nominal venting of the Carbon Dioxide Removal Assembly (CDRA) also located on ISS Node 3. The similarity between the total pressure and the sum of the partial pressures is also evidence that materials outgassing is not a large component of the ISS induced environment. The RGA mass-to-charge ratio of 1 to 100, and even the smaller range of 3 to 50 represented in Figure 18, is sufficient for characterizing the ISS induced environment.

The known vented species from each system are also correlated with the RGA partial pressure measurements, shown in Figure 19. The CDRA system vents scrubbed carbon dioxide from the ISS and, as expected, the mass-to-charge ratio of 44 , corresponding to $\mathrm{CO}_{2}$, has the highest partial pressure during the CDRA vent spike. Mass-to-charge ratios related to additional CDRA effluent species also experience a spike corresponding to the CDRA vent (mass-to-charge ratios of 14, 16, and 28). The Russian segment vents water $\left(\mathrm{H}_{2} \mathrm{O}\right)$, and this is represented by the small spikes in mass-to-charge ratio of 18. The mass spectrum of water includes mass-to-charge ratio of 17 , which explains the small spikes at the same time as the spikes in mass-to-charge ratio of 18, as opposed to an unknown source of ammonia. Consistent with methane $\left(\mathrm{CH}_{4}\right)$, there are significant dips in mass-to-charge ratios of 14, 15, and 16 during the time of the Sabatier vent.

The background level of AMU 17 was also similar to the background level from the ram-facing background scan, despite the influence of water venting from the Russian segment. 


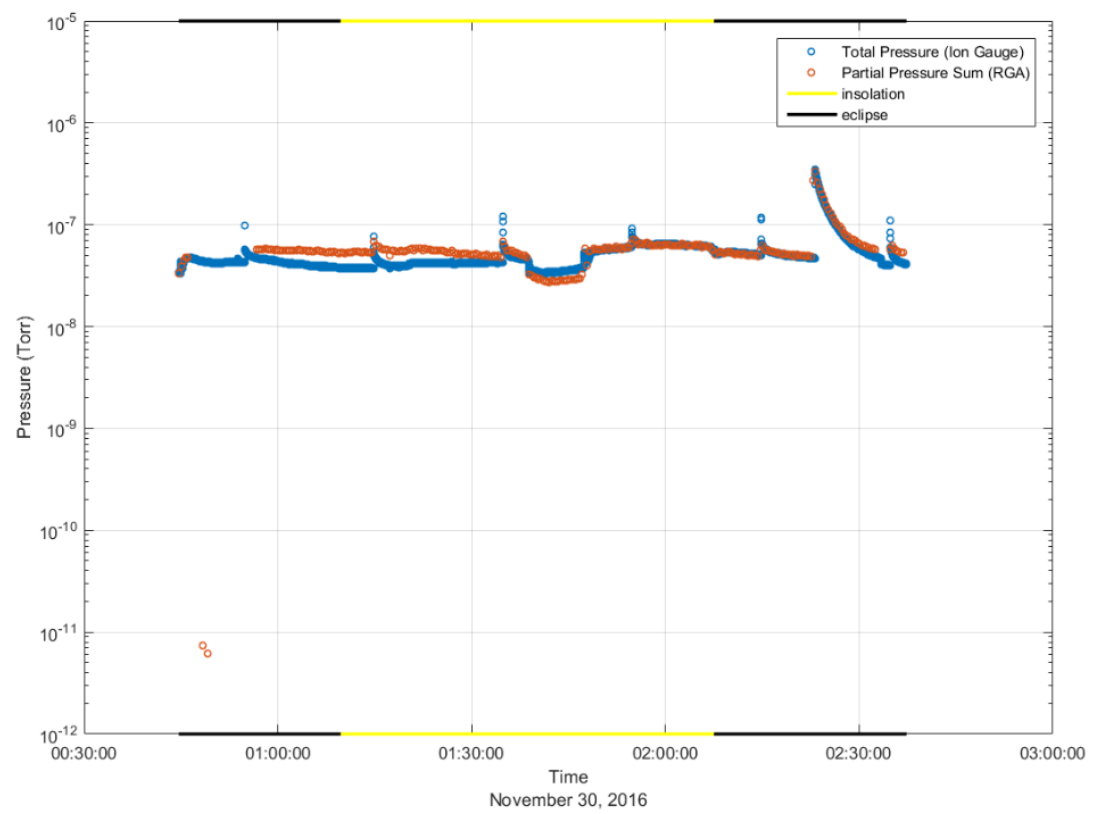

Figure 18: Total pressure and sum of partial pressure range (amu 3 to 50) measured by RELL in the wake (-X) scanning position.

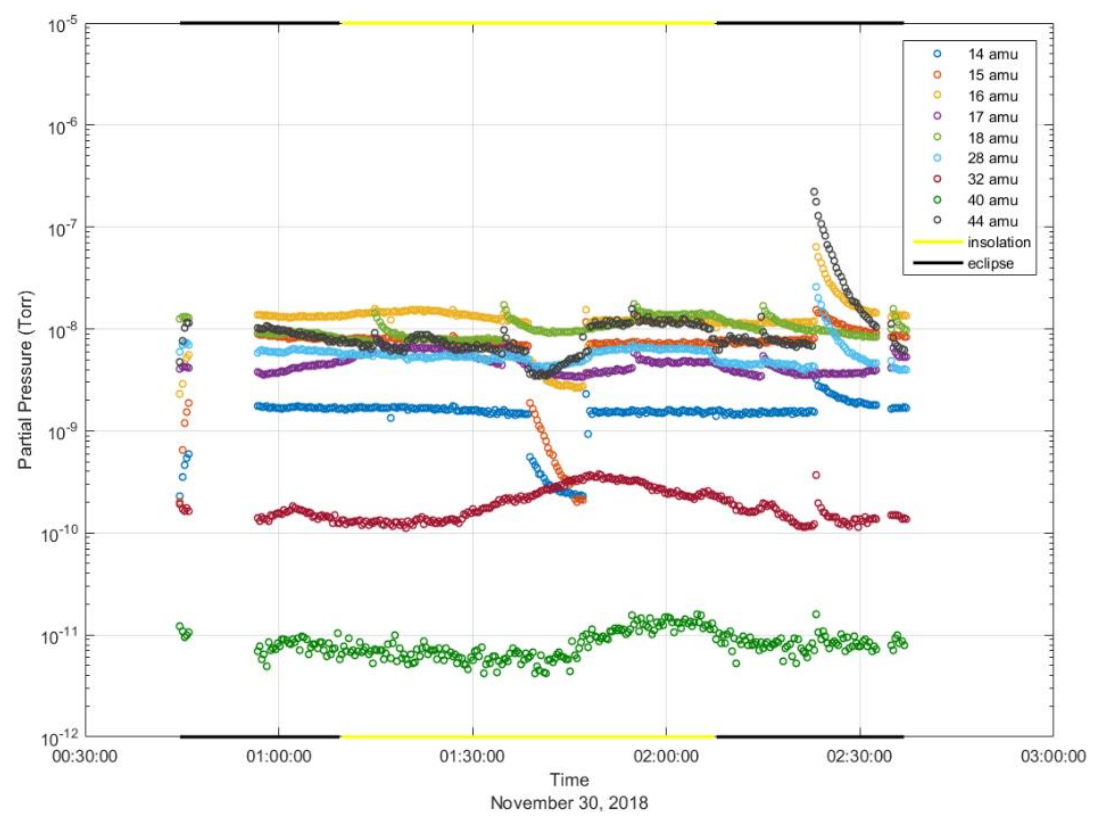

Figure 19: Selected partial pressures measured by the RGA in the wake (-X) scanning position.

\subsection{Background Scanning B}

The second set of background scanning activities focused on faces 1,2, and 6 of the ISS P1 Truss segment, each with a ram facing component (see Figures 5 and 6). After each face scan with RELL pointing directly at the truss face, RELL was rotated $22.5^{\circ}$ and $45^{\circ}$ in both the ISS starboard $(+Y)$ and port $(-Y)$ directions. The ion gauge total pressure measurements for each truss face are shown in Figures 20,22, and 24, where the most noticeable features - the spikes and dips in pressure - are correlated to the times of ISS ECLSS vents. The tall spikes correspond to CDRA venting carbon 
dioxide, the dips correspond to the Sabatier venting methane, and the much smaller peaks most noticeable on truss face 2 are from the Russian segment ECLSS water vent. Similarly, the species from these vents, corresponding to spikes and dips in the relevant partial pressures measured by the RGA, are shown in Figures 21, 23, and 25. The partial pressure plot highlights another venting activity: the large spike in mass-to-charge ratio of 40 in Figure 21 corresponds to the venting of argon from the European Space Agency (ESA) Columbus module.

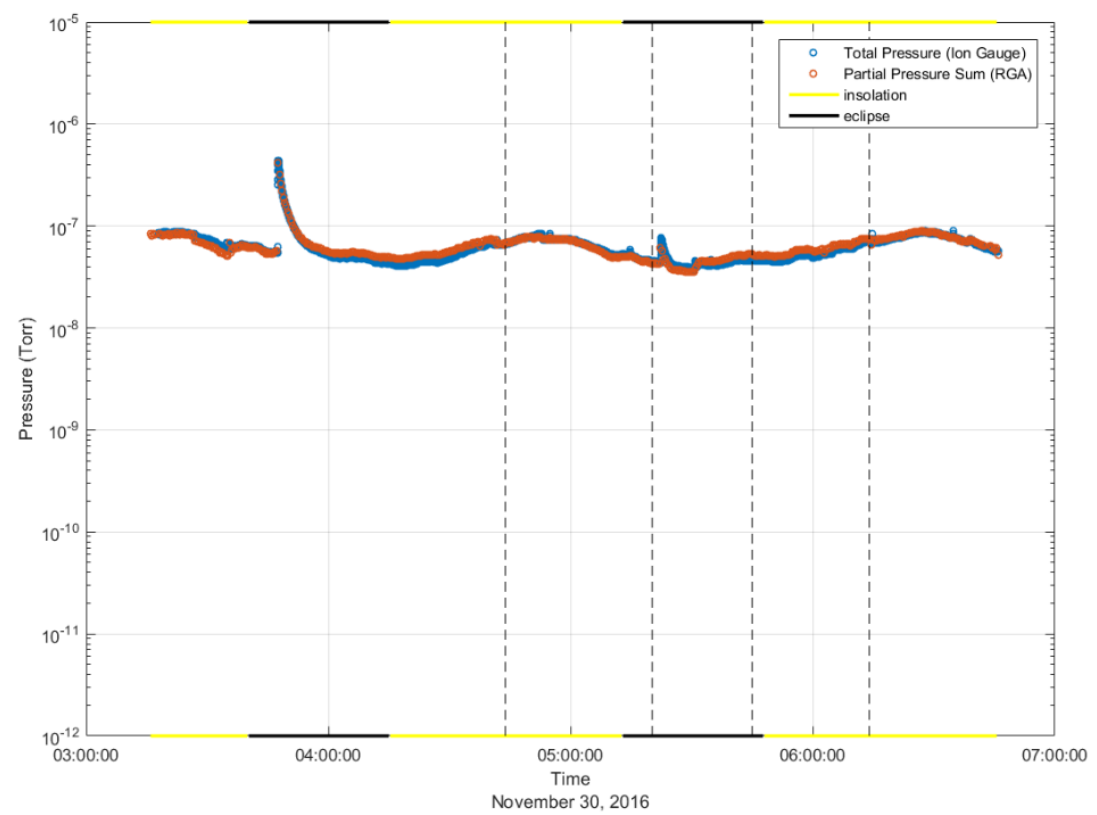

Figure 20: Total pressure measured by RELL during P1 Truss background scans of truss face 1.

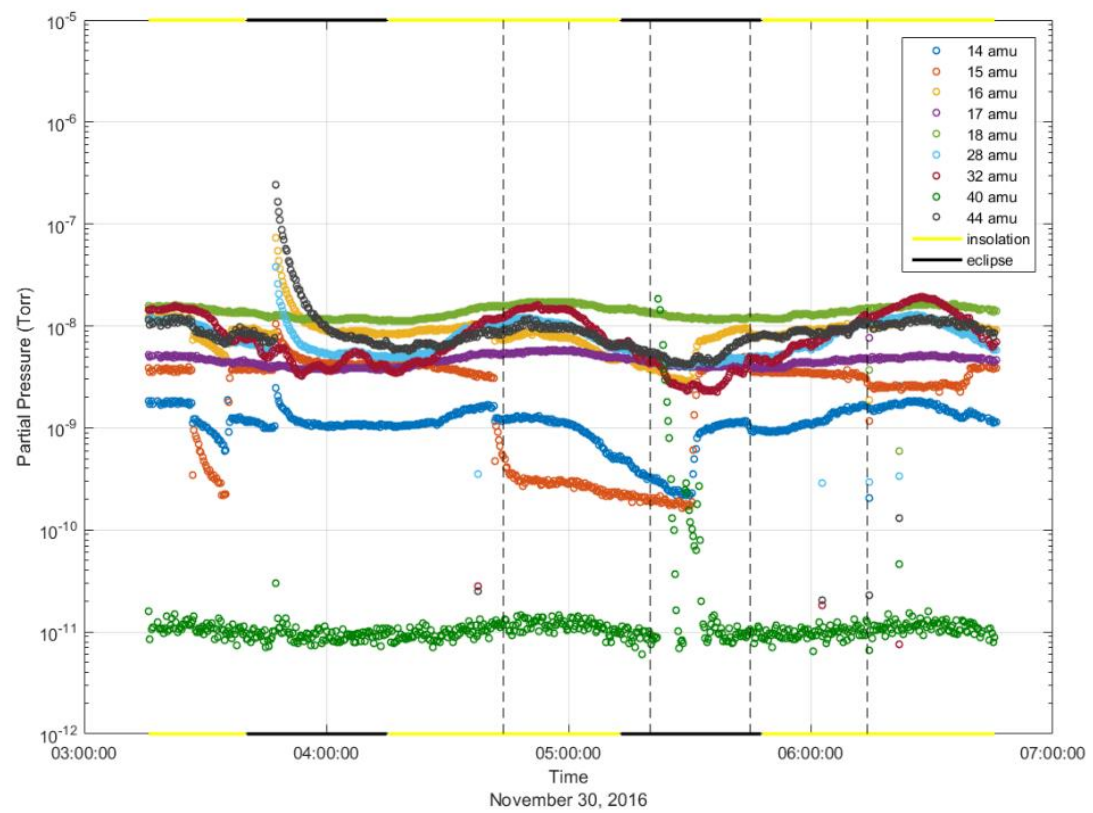

Figure 21: Selected partial pressures measured by RELL RGA during P1 Truss background scans of truss face 1. 


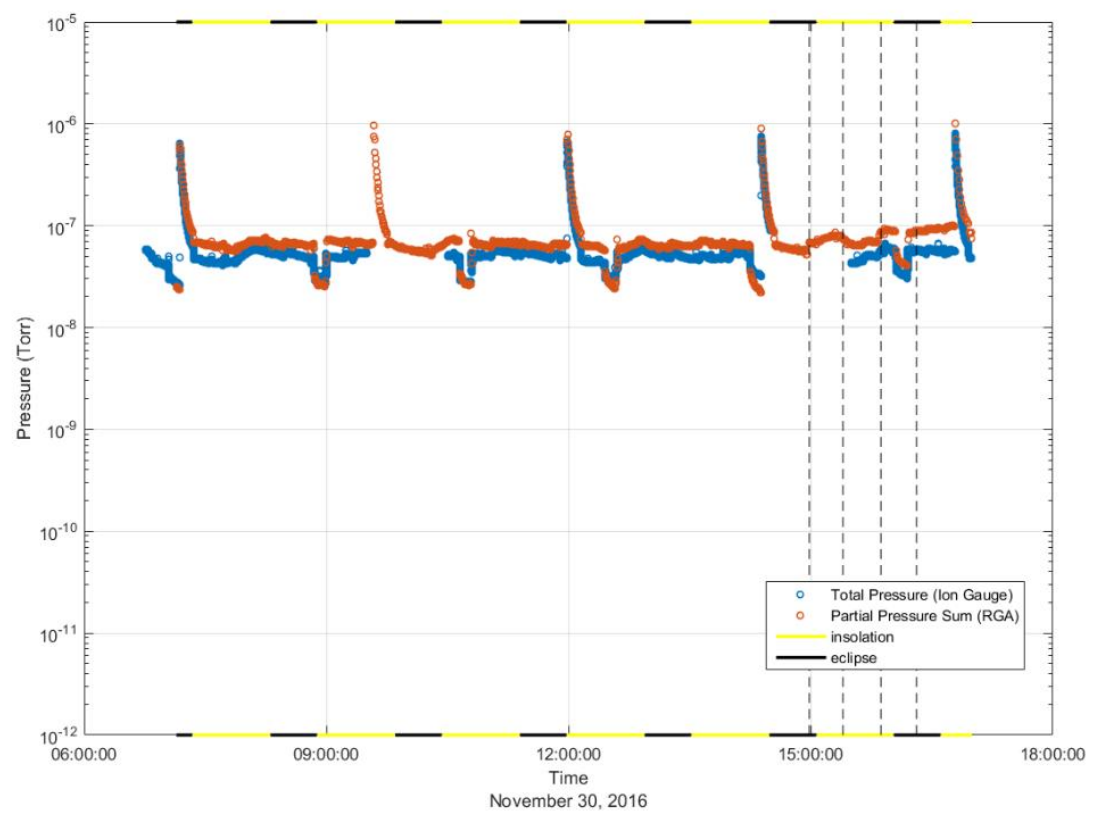

Figure 22: Total pressure measured by RELL during P1 Truss background scans of truss face 6.

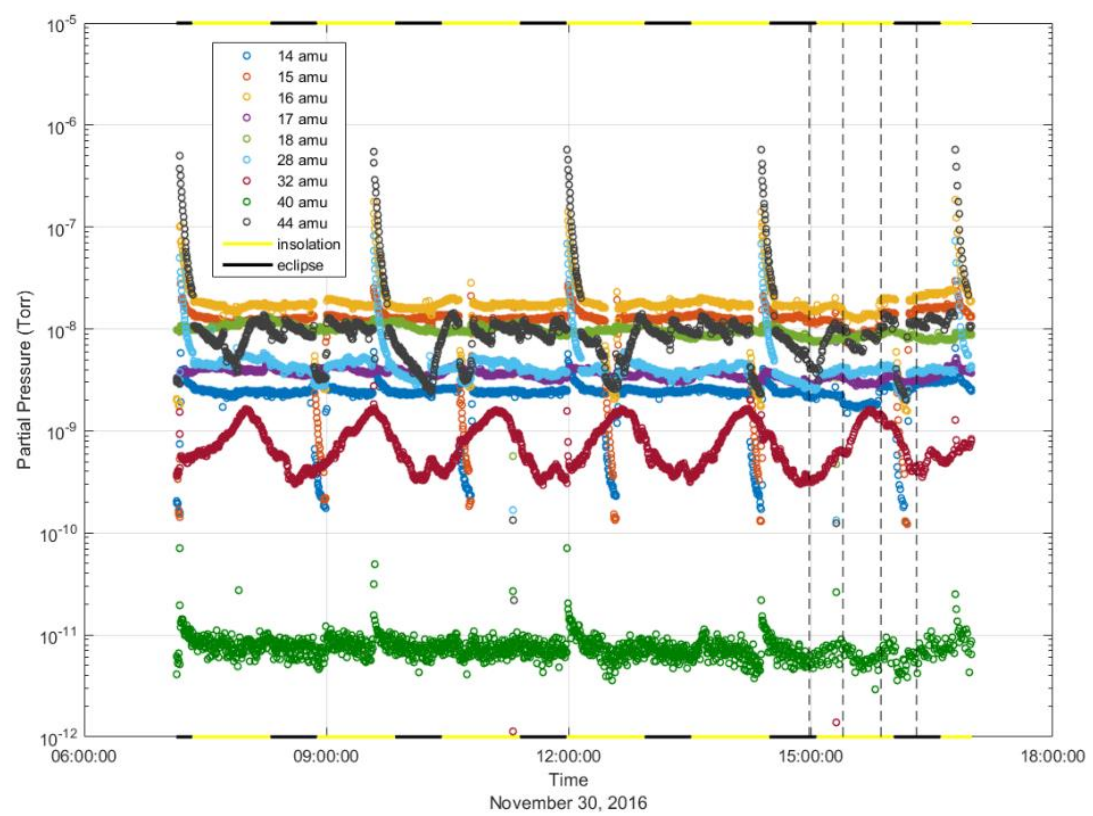

Figure 23: Selected partial pressures measured by RELL RGA during P1 Truss background scans of truss face 6. 


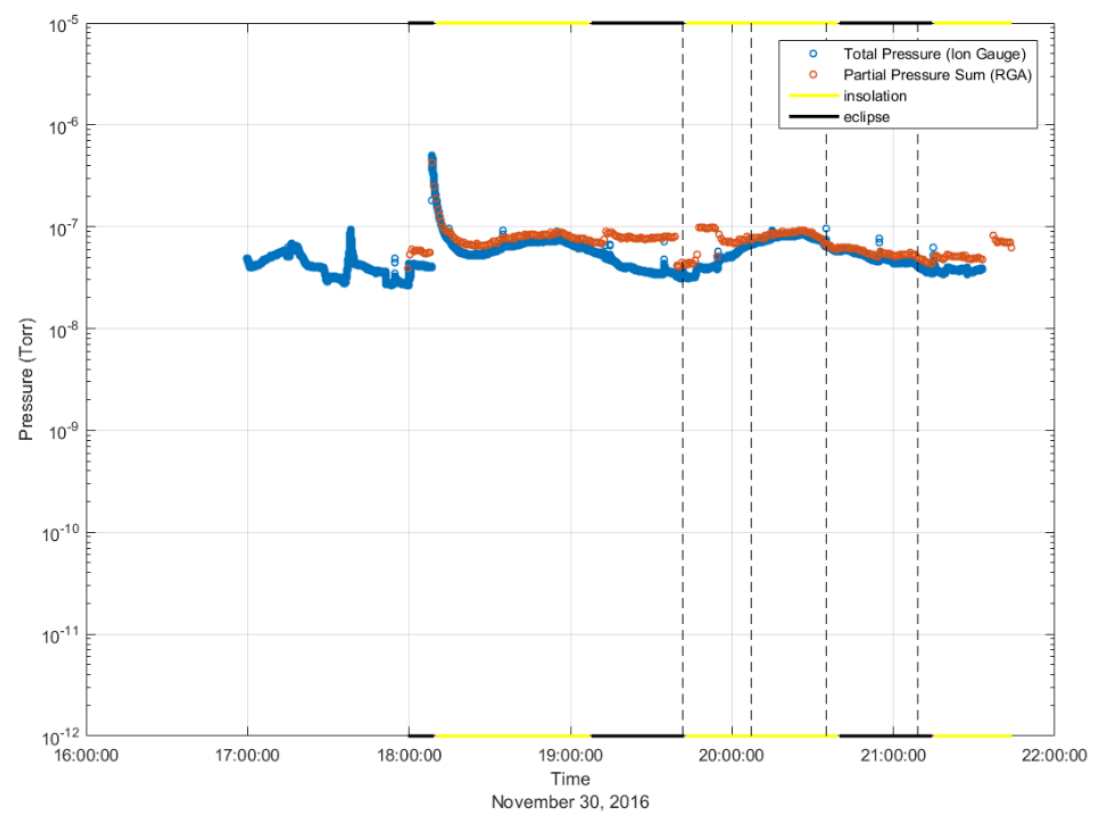

Figure 24: Total pressure measured by RELL during P1 Truss background scans of truss face 2.

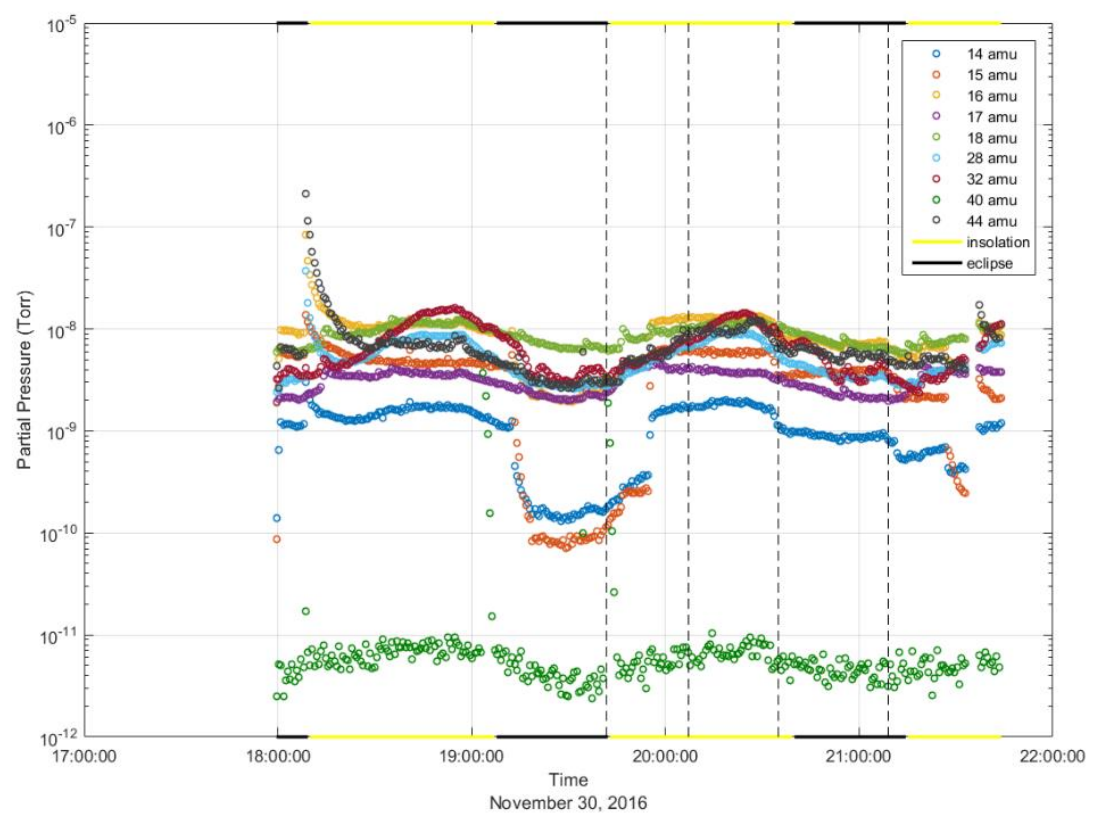

Figure 25: Selected partial pressures measured by RELL RGA during P1 Truss background scans of truss face 2.

A characterization of the induced environment around the truss, relative to the natural environment, can be made by comparing the background scanning activities of the truss with the activities of Background Scanning A. The levels of mass-to-charge ratio of 16 increased by approximately an order of magnitude. The levels of mass-to-charge ratios of 17 and 18 remained consistent with the levels seen during Background Scanning A.

Since the truss background scans occurred during several orbits, the diurnal effect on total pressure and partial pressure measurements can be seen. The most noticeable sinusoidal shape caused by the diurnal effect is seen by the mass-to-charge 
ratio of 32, corresponding to oxygen $\left(\mathrm{O}_{2}\right)$. The average partial pressure of mass-to-charge ratio 32 decreases significantly when RELL is pointed directly wake, which causes the total pressure to have less of a sinusoidal shape during that period.

\subsection{Background Scanning C}

The final set of background scanning activities focused on the middle port-side EATCS radiator to understand the induced environment surrounding the radiators and Radiator Beam Valve Modules (RBVMs), where an ammonia leak was suspected before beginning RELL operations. Scanning was performed at three places along the radiator: 1) at the base, 2) 8 feet from the base, and 3) 16 feet from the base. At each location, RELL was pointed directly ISS nadir (+Z) at the radiator, then rotated $22.5^{\circ}$ and $45^{\circ}$ both ISS forward/ram $(+X)$ and aft/wake $(-X)$ from the nadir pointing position (see Figures 7 through 11).

The total pressure and partial pressures for the background scans at the base of the radiator are shown in Figures 26 and 27, respectively. Figures 28 and 29 show the total and partial pressure measurements for the background scans at the location 8 feet from base of the radiator. Figures 30 and 31 show the total and partial pressure measurements for the background scans at the location 16 feet from the base of the radiator.

At each location and orientation along the radiator, the venting activities of CDRA, Sabatier, and the Russian segment ECLSS are detected. The timelines and detected species correspond to venting timelines provided by the hardware owners.

Once again, the diurnal effect, particularly for mass-to-charge ratios of 16 and 17, is clear, with the peak of each curve occurring shortly after eclipse. The sinusoidal shape of total pressure is also driven by mass-to-charge ratios 16 and 17 . However, this is different from the major contributor to the sinusoidal shape of total pressure in Background Scanning B activities, which was mass-to-charge ratio 32 .

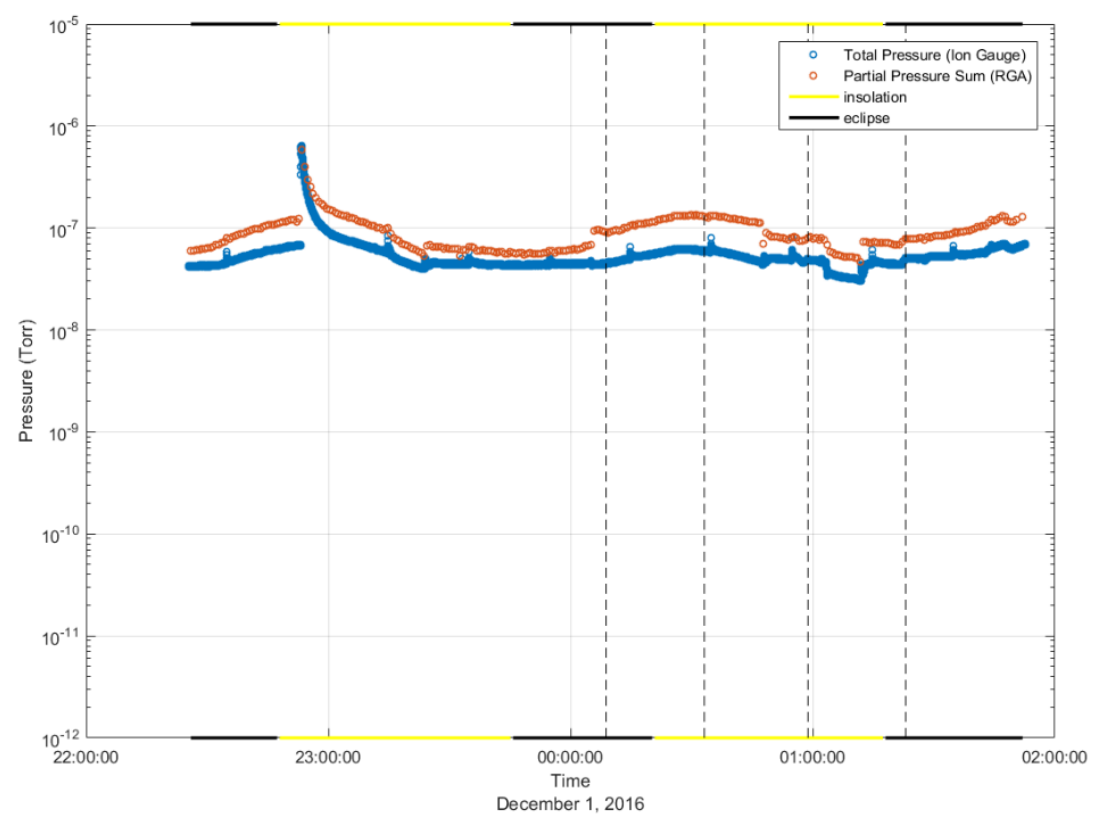

Figure 26: Total pressure measured by RELL during EATCS radiator background scans at base of radiator. 


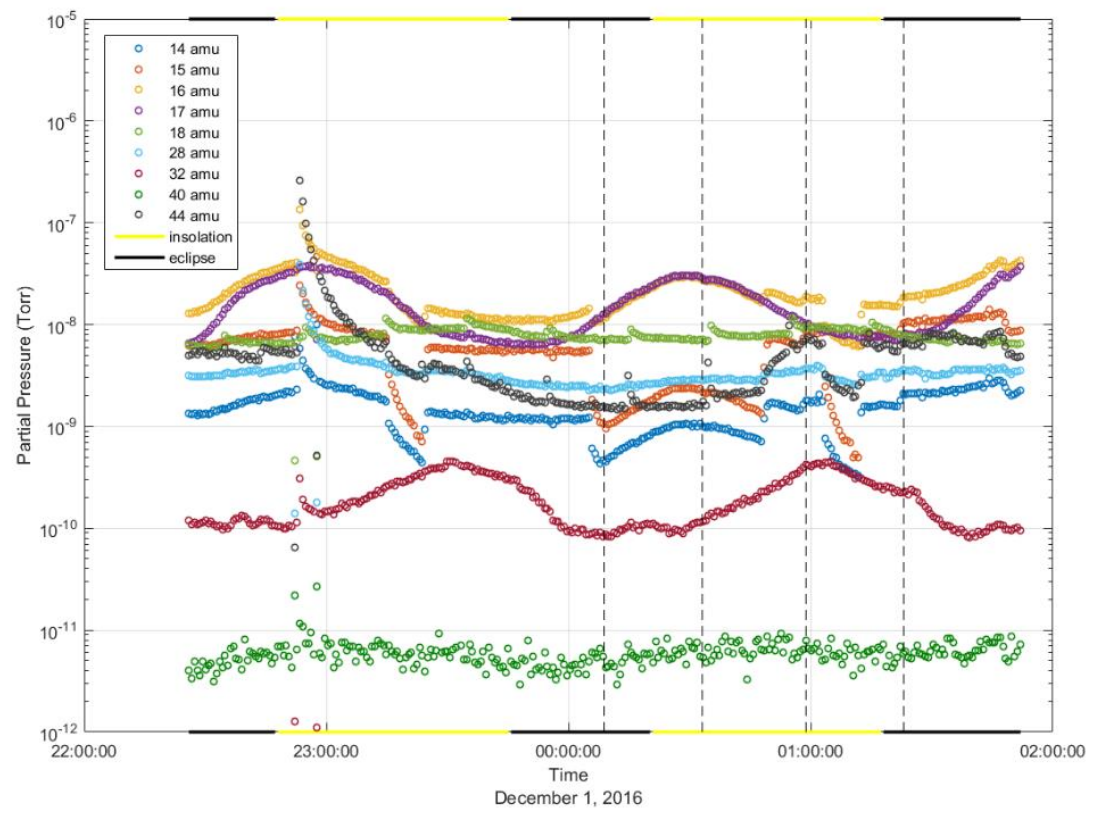

Figure 27: Selected partial pressures measured by RELL RGA during EATCS radiator background scans at base of radiator.

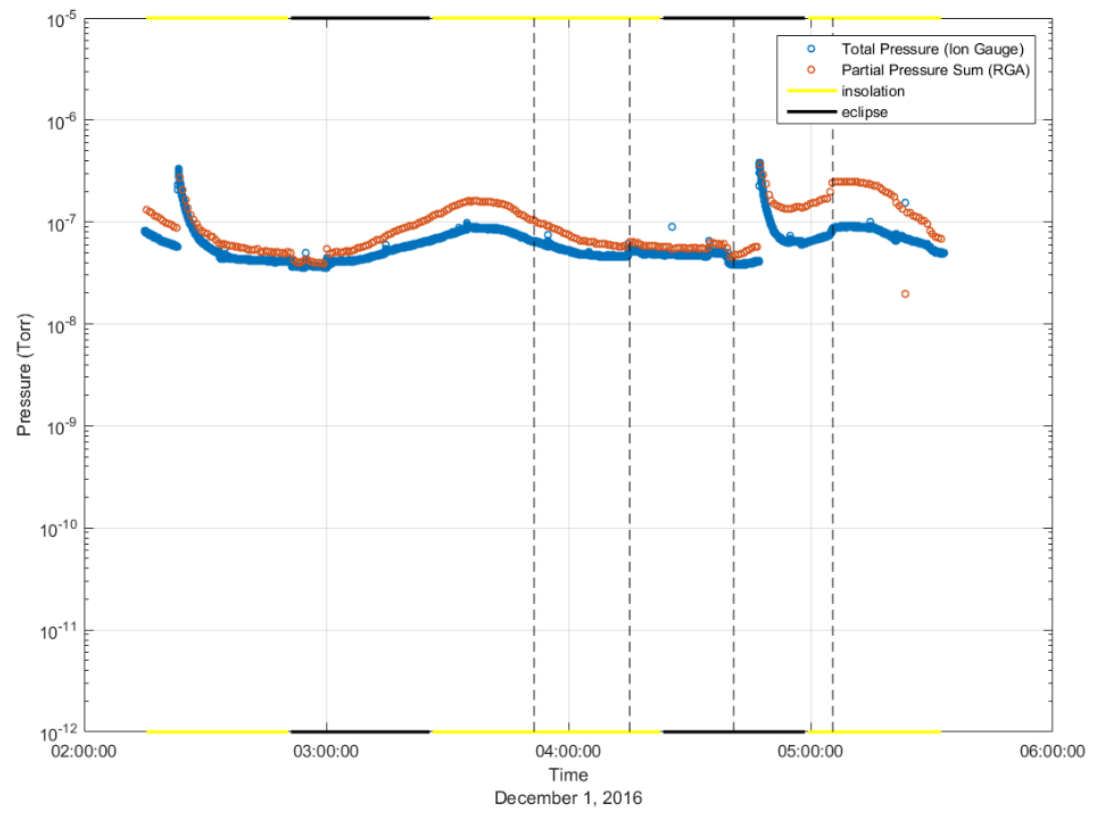

Figure 28: Total pressure measured by RELL during EATCS radiator background scans at 8 feet from base of radiator. 


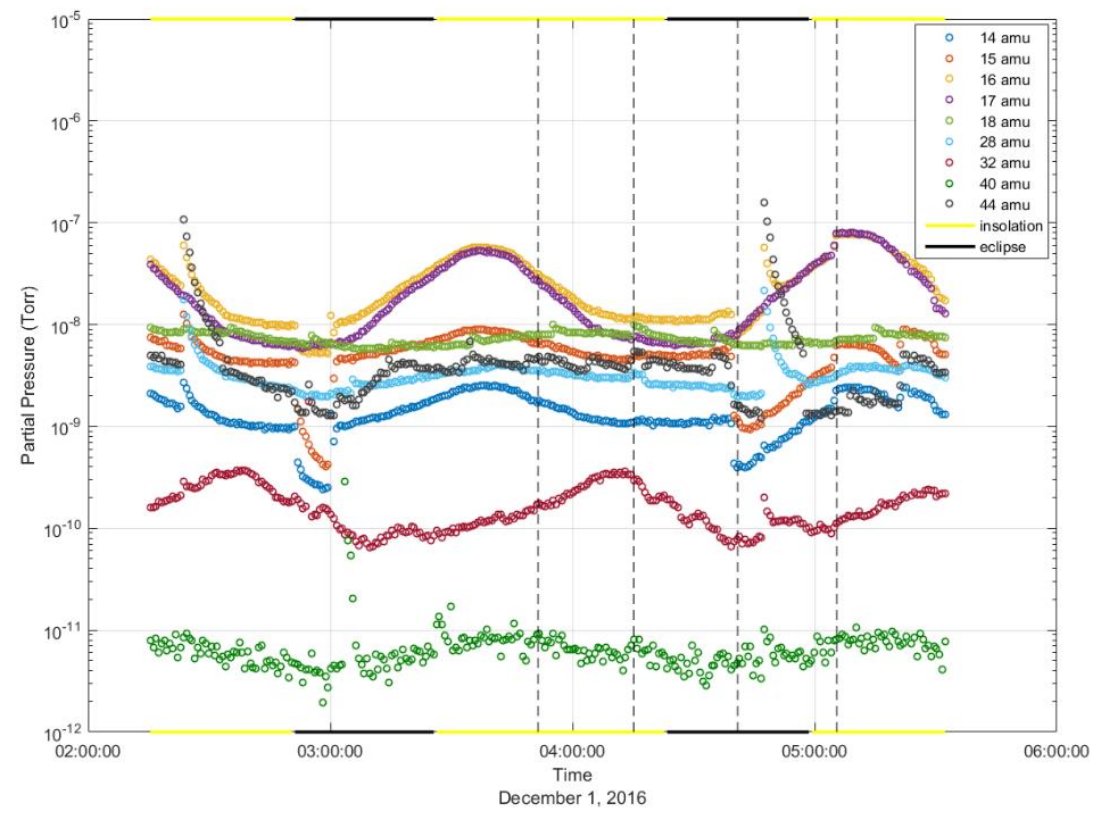

Figure 29: Selected partial pressures measured by RELL during EATCS radiator background scans at 8 feet from base of radiator.

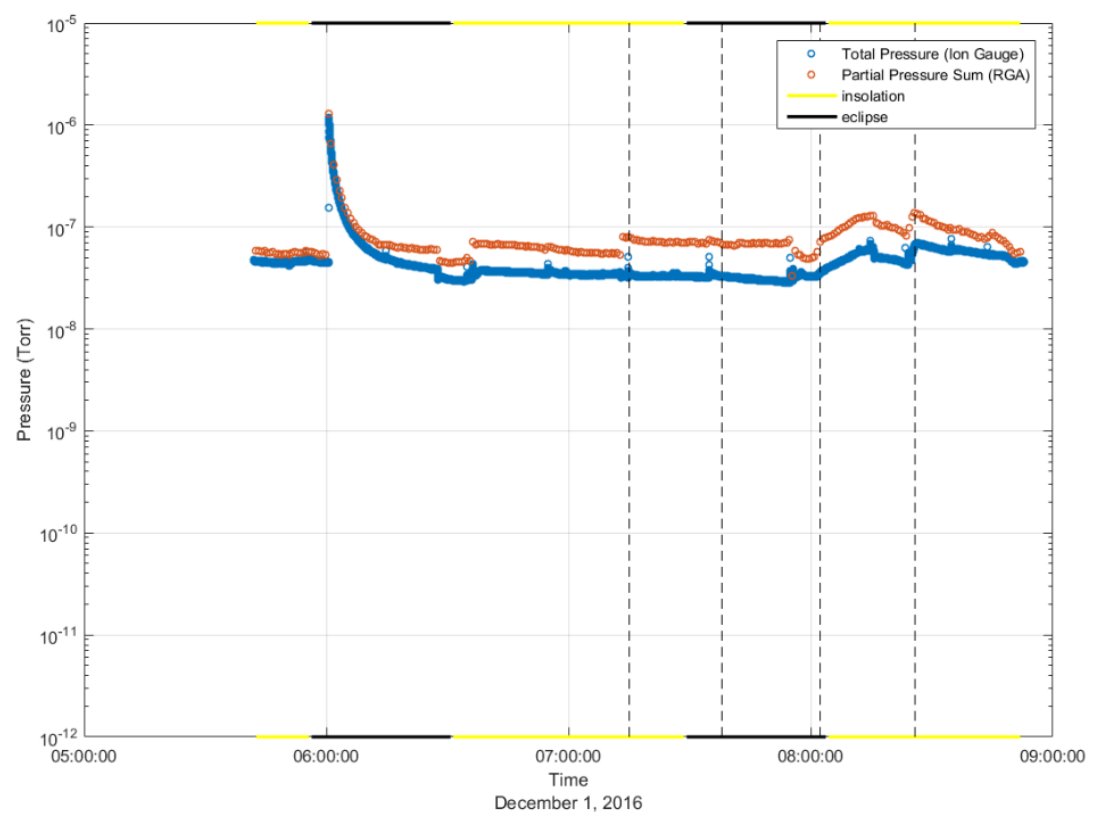

Figure 30: Total pressure measured by RELL during EATCS radiator background scans at 16 feet from base of radiator. 


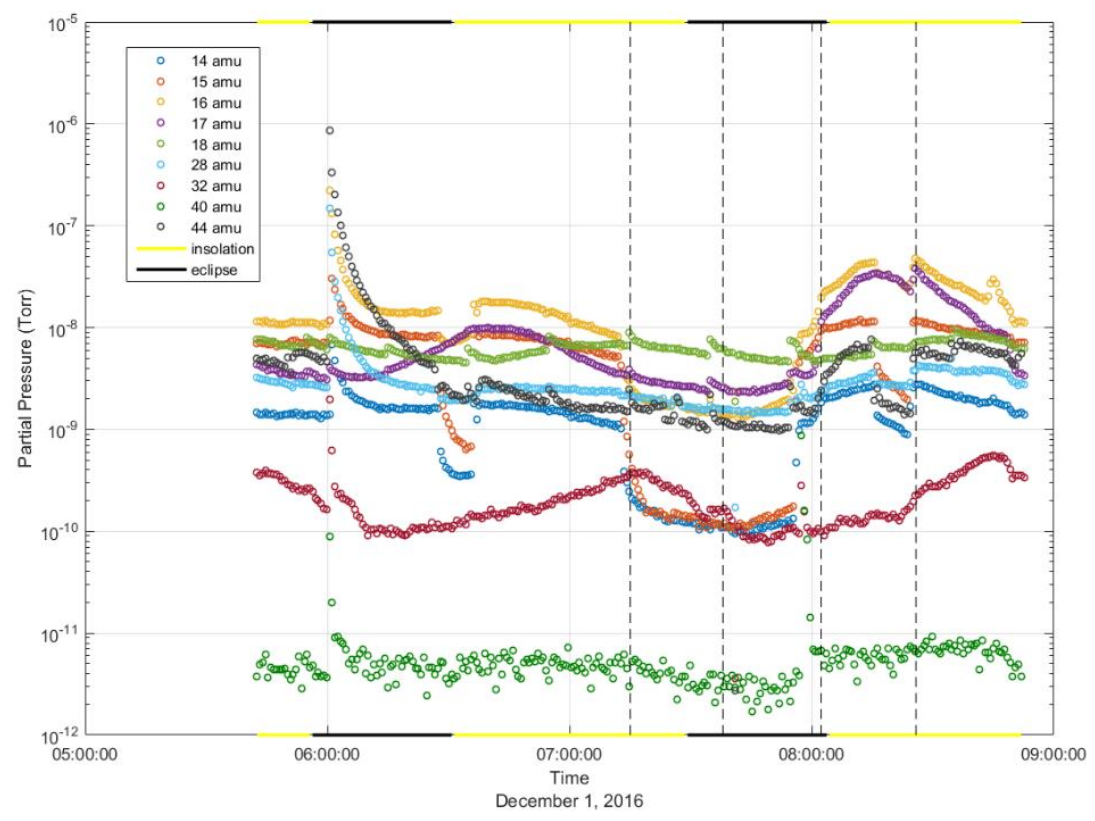

Figure 31: Selected partial pressures measured by RELL during EATCS radiator background scans at 16 feet from base of radiator.

When RELL is rotated in the ram $(+\mathrm{X})$ direction towards the RBVMs, mass-to-charge ratios 16 and 17 together have upward shifts in pressure. Interestingly, this increase is largest when RELL is furthest away from the radiator base and RBVMs, likely because the RBVM was, in fact, leaking ammonia. The field of view of the RGA is largest at 16 feet from the base of the radiator and the RBVM is most prominent in the furthest field of view. There may be a similar downward shift in pressure when RELL rotates from $45^{\circ}$ in the ram direction to directly nadir, but it is a small change. The fact that mass-to-charge ratios 16 and 17 are trending together indicates there is ammonia in the environment around the radiators. However, it is possible the presence of ammonia is due solely to the ammonia leak in the RBVM and ammonia would not be present in a scan of a 'leak-free' radiator and RBVM environment. Regardless of the reason for the presence of ammonia, mass-to-charge ratio 16 is higher than 17 which means other constituents are in the induced environment, in addition to ammonia. The increase in mass-to-charge ratio 16 when pointing in the ram direction is likely due to atomic oxygen.

\section{CONCLUSIONS}

The RELL on-orbit demonstration was successful in ammonia leak detection and location, which was facilitated by a thorough understanding of the sensitivity of RELL in the natural and induced environment around ISS.

The RGA measurements of several mass-to-charge ratios, including 16 or atomic oxygen, were affected by the ISS negative floating potential when scans were performed in the ram-facing direction. A clean environment without ISS structure was not achieved when scans were performed in the wake direction, but it was clear the RELL instruments detected several ECLSS vents from across the station, both on the US Operating Segment and the Russian segment. The vent times were corroborated with vent information from hardware owners. The ability of RELL to detect the ECLSS vents persisted through the background scans of the P1 Truss faces and the port-side radiator panel. ${ }^{11}$

Ammonia was detected in the environment around the port-side radiator panels and RBVMs. The level of ammonia increased as the view of the RBVMs improved when RELL moved away from the base of the radiator and rotated towards the RBVMs. This is likely due to an ammonia leak from the RBVM, rather than a consistent presence of ammonia in the induced environment.

As a result, it is important to communicate with owners of hardware that may be venting during RELL operations, regardless of where the vent is relative to the RELL scanning location. Important information to obtain is venting time, duration, and constituents. 


\section{ACKNOWLEDGEMENTS}

The authors gratefully acknowledge Jesse A. Buffington, David Autrey, Carlos E. Soares, Matthew J. Roode, Steven B. Morris, and Michael S. Woronowicz for their contributions during the design and verification phase of the Robotic External Leak Locator. The authors would also like to acknowledge Matt Kowitt and Dave Doheny of Stanford Research Systems for their support during the RELL on-orbit operations on the International Space Station.

\section{REFERENCES}

[1] https://www.nasa.gov/pdf/473486main_iss_atcs_overview.pdf.

[2] Naids, A., Bond, T., Johnson, B., Rossetti, D., Huang, A., Deal, A., Fox, K., Heiser M., Hartman, W., and Mikatarian, R., "The Demonstration of a Robotic External Leak Locator on the International Space Station," International Space Station Research and Development Conference 2017, Washington, D.C., July 17-20, 2017.

[3] Deal, A., et al. "Robotic External Leak Locator (RELL) leak plume field detection on the International Space Station (ISS)," SPIE Conference August 20, 2018.

[4] Woronowicz, M., et. al., "Analytical and Experimental Studies of Leak Location and Environment Characterization for the International Space Station", AIP Conference Proceedings 1628, 547 (2014).

[5] Lieszkovszky, L., Filippelli, A.R., and Tilford, C.R., "Metrological characteristics of partial pressure analyzers", J. Vac. Sci. Technol. A. 8, 3838-3854 (1990).

[6] http://www.thinksrs.com/downloads/PDFs/Manuals/RGAm.pdf.

[7] https://www.pfeiffer-vacuum.com/productPdfs/PTR26000.en.pdf.

[8] http://esmat.esa.int//Materials_News/ISME09/pdf/10-In-flight/Tighe.pdf.

[9] Krylov, A.N., and Mishina, L.V., "On-orbit Experiments On Pressure Change Research In Ambient Space Vehicle Environment," $25^{\text {th }}$ International Symposium on Rarefied Gas Dynamics Proceedings, Saint Petersburg, Russia, 561 566 (2007).

[10] https://www.nasa.gov/sites/default/files/104840main_eclss.pdf.

[11] Huang, A., et al. "International Space Station (ISS) Environmental Control and Life Support (ECLS) vent flow reflection and detection by the Robotic External Leak Locator (RELL)," SPIE Conference, August 20, 2018.

[12] Kelley, M. C., [The Earth's Ionosphere: Plasma Physics and Electrodynamics], Academic Press, (1989).

[13] Tascione, T. F., [Introduction to the Space Environment, Second Edition], (1994).

[14] Hargreaves, J. K., [The solar-terrestrial environment], Cambridge University Press, (1992).

[15] https://webbook.nist.gov.

[16] https://ccmc.gsfc.nasa.gov/modelweb/models/nrlmsise00.php. 